\title{
Jurors' Perceptions of an Elderly Eyewitness:
}

Effects of Geriatric Diagnosis, Level of Care, and Age

$$
\text { by }
$$

Elizabeth Anne Schultheis

A thesis submitted to the Faculty of Graduate and Postdoctoral Affairs in partial fulfillment of the requirements for the degree of

Master of Arts

in

Psychology

Carleton University

Ottawa, Ontario

(C) 2015, Elizabeth Anne Schultheis 


\begin{abstract}
Mock jurors' perceptions of older adult eyewitnesses was assessed by testing how age, geriatric diagnosis, and level of care influences decision making. Mock jurors $(N=355)$ were asked to read a trial transcript that varied age of eyewitness: 45 years, vs. 65 years, vs. 85 years; Level of care: home vs. long-term care facility; and Geriatric disease: none, vs. early stage dementia. Mock jurors then rendered a verdict, provided ratings of the eyewitness, and completed a measure of stereotypes. Although no direct effect on verdict was found, verdict confidence was influenced in a statistically significant way by the presence of a geriatric diagnosis. Subscribing to negative stereotypes of older adults was found to be related to higher ratings of senility. The findings indicated that mock jurors are influenced by geriatric diagnosis, as it negatively impacts their confidence in their verdict. Limitations and future directions will be discussed.
\end{abstract}




\section{Acknowledgements}

First, I would like to express my sincere thanks and gratitude to my advisor, Dr. Joanna Pozzulo, for the many hours you have spent assisting me throughout the process of writing this thesis. I am thankful for your support throughout this process and for your unwavering understanding. Your feedback and constructive criticism have challenged me to better myself. Without your guidance and support this paper would not be what it is.

I would also like to extend my gratitude to my committee members, Dr. Evelyn Maeder and Dr. Diana Majury, for your insightful and invaluable feedback and guidance in creating this document. Thank you so much for taking the time to be on my committee.

Many thanks are also extended to Etelle Bourassa who has been a consistent source of hope and positive motivation. I truly acknowledge all you have done and how you continue to go the extra mile for me. I very much appreciate it.

Finally, I would like to offer special thanks to my friends and family, you have all shown me kindness and unwavering support throughout all the stages of this journey. To my friends and peers Holly and Emily, I thank you so much for being a sounding board for my endless tirade of questions, ideas, and theories. Your support and encouragement through the last two years has made all the difference to me. Thank you. Brittany, although you finished your journey through school before me, you have been a source of encouragement, positive thoughts, and love. We have been through so much together over the years and have grown so much, you are always there for me when I need you. I could never thank you enough. Mitch, thank you for sticking by me through this journey. You have been there for every moment, high or low, a constant and unwavering force of calm, which is always just what I need. Thank you for supporting me through this 
process. You have been a true rock and I love you. Last but not least to my Mom and Grandparents, I could never possibly count all the ways that you have helped me make it to today. Thank you for all your time, love, and continual support emotionally, financially, and every other way. You have always been there for me and I am always confident of one thing: that you are my biggest fans no matter what I do. I love you. 


\section{Table of Contents}

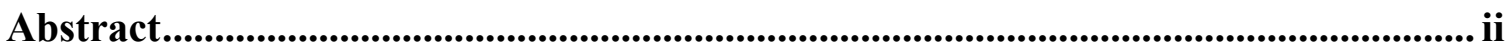

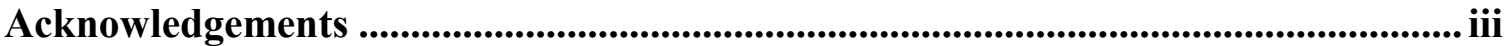

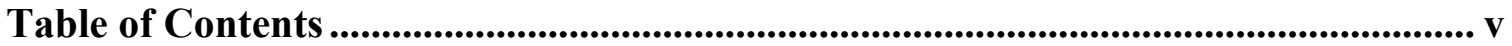

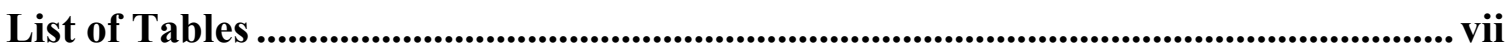

List of Appendices.......................................................................................................... ix

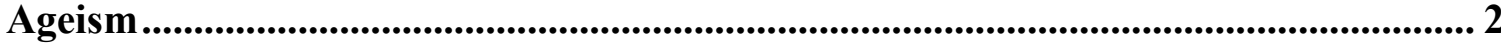

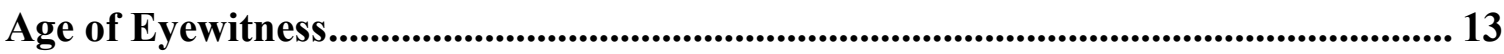

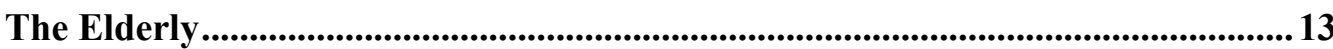

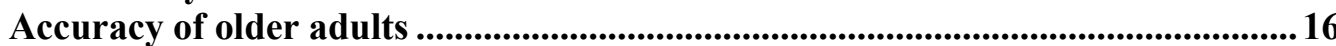

Jurors' perceptions of the elderly ......................................................................................... 19

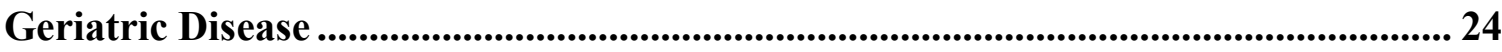

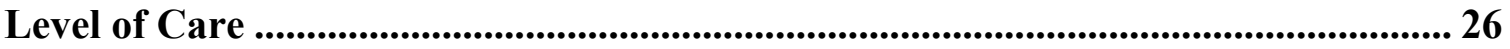

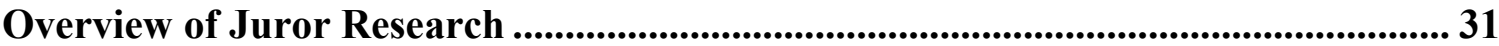

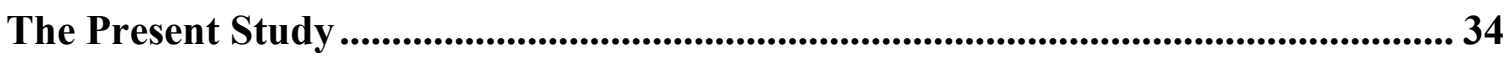

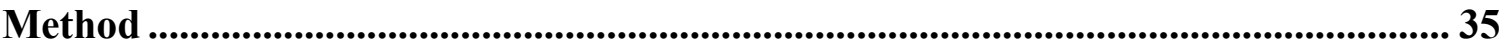

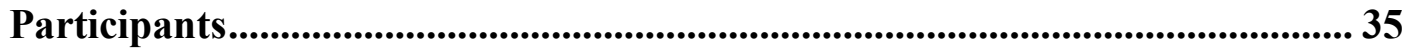

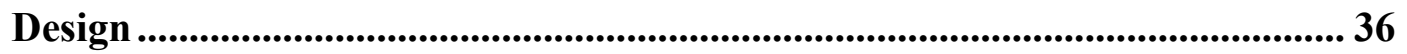

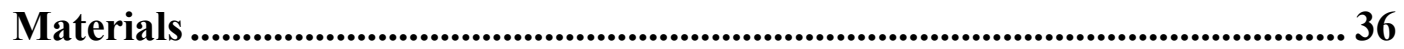

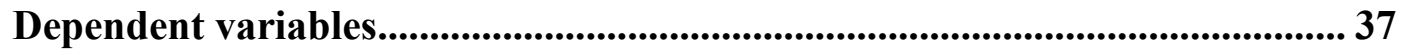

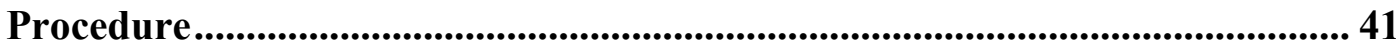

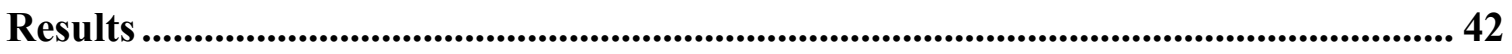

Preliminary Analyses............................................................................................. 42

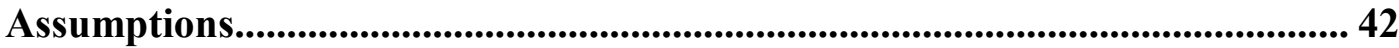

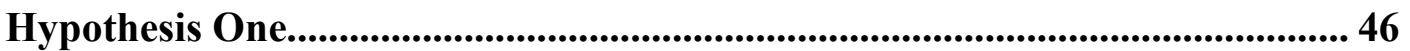


Hypothesis Two ……........................................................................................................ 47

Confidence in verdict: Not Guilty verdicts.........................................................................48

Confidence in verdict: Guilty verdicts ................................................................................51

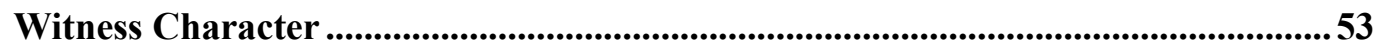

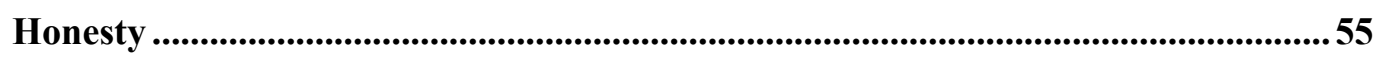

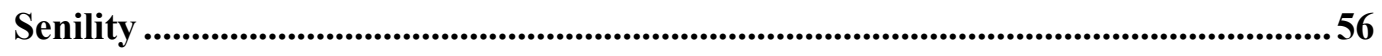

Hypotheses Three.......................................................................................................... 58

Hypotheses Four................................................................................................................... 61

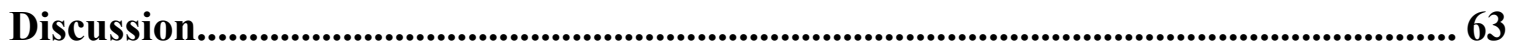

Limitations....................................................................................................................... 69

Future Research ............................................................................................................ 72

Implications ..................................................................................................................... 74

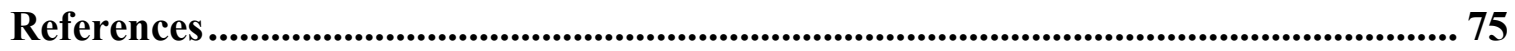

Appendix A: Informed Consent ............................................................................................. 87

Appendix B: Demographic Measure .................................................................................... 89

Appendix C: Trial Transcript................................................................................................. 90

Appendix D: Verdict Form ........................................................................................... 96

Appendix E: Sentencing Form............................................................................................. 97

Appendix F: Manipulation Check ........................................................................................... 98

Appendix G: Eyewitness Ratings ............................................................................................ 99

Appendix H: Opinion Scales ........................................................................................... 101

Appendix I: Stereotypes Toward Older People Scale (STOPS) ................................... 104

Appendix J: Debriefing Form ............................................................................................ 107

Appendix K: Consent to Keep Data ................................................................................. 110 


\section{List of Tables}

Table 1 Omnibus results of logit analyses of verdict, age, geriatric diagnosis, and level of care. 46

Table 2 Marginal Means (M) and Standard Deviations (SD) for confidence in verdict when a not guilty verdict is rendered.

Table 3 Marginal Means (M) and Standard Deviations (SD) for confidence in verdict

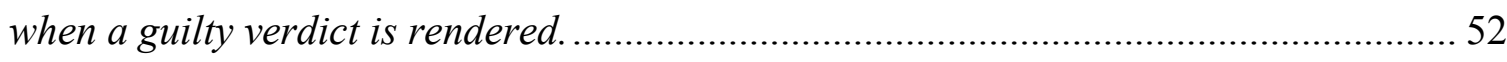
Table 4 Marginal Means (M) and Standard Deviations (SD) in eyewitness character. .. 54 Table 5 Marginal Means (M) and Standard Deviations (SD) for honesty. 55 Table 6 Marginal Means (M), Standard Deviations (SD) for perceived senility of the eyewitness.

Table 7 Results from a multiple regression assessing whether age, geriatric diagnosis, level of care, and total score on the STOPS predicted mock jurors ratings of eyewitness senility.

Table 8 Results from a multiple regression assessing whether age, geriatric diagnosis, level of care, total score on the STOPS, and verdict predicted mock jurors ratings of eyewitness senility. 


\section{List of Figures}

Figure 1 Four groups based on Fiske et al. (2002) function of perceived warmth and

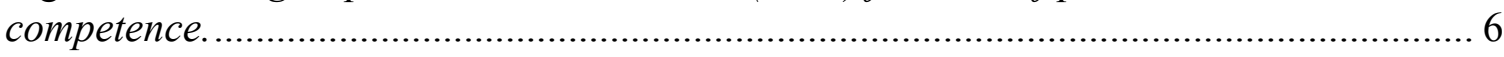




\section{List of Appendices}

Appendix A: Informed Consent .............................................................................. 87

Appendix B: Demographic Measure ............................................................................. 89

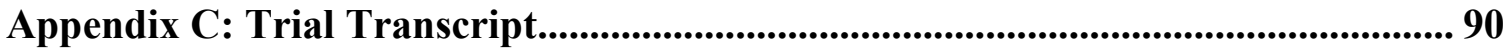

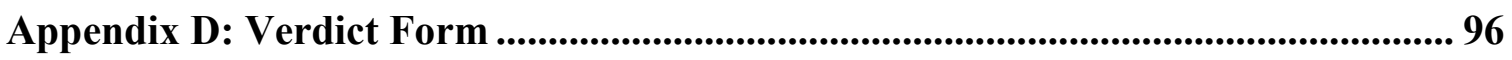

Appendix E: Sentencing Form............................................................................. 97

Appendix F: Manipulation Check ............................................................................... 98

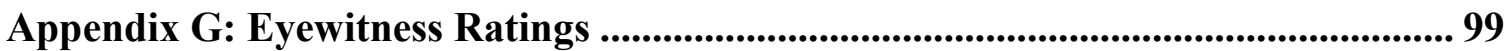

Appendix H: Opinion Scales ..................................................................................... 101

Appendix I: Stereotypes Toward Older People Scale (STOPS) ................................. 104

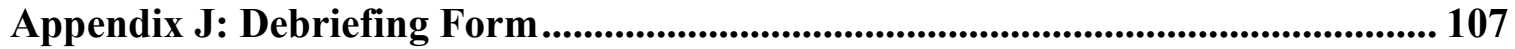

Appendix K: Consent to Keep Data ..................................................................................... 110 
Jurors' Perceptions of an Elderly Eyewitness:

Effects of Geriatric Diagnosis, Level of Care, and Age

The primary purpose of this study is to examine the influence of eyewitness age (older adults) on jurors' perceptions. In Canada, there has been little investigation of the concerns facing elderly adult victims and witnesses throughout the criminal justice system, despite the recent increase in concern for their rights and protection. For example, in $R v$. Khelawon (2006), a nursing home manager was accused of aggravated assault against five residents. However, by the time of the trial only one of the residents was still alive, the remainder having died from causes unrelated to the assault. The police video statements of the residents, who were not able to testify, were deemed admissible in court. The nursing home manager was found guilty in the cases of two residents. Conversely, on appeal, the videotaped statements were deemed inadmissible and the manager was acquitted of all charges. In this case, the delay between incident and trial resulted in the majority of complainants passing away, this prevented them from getting their fair day in court, which demonstrates one of the unique considerations when older adults are the victims of crime or relied on for eyewitness statements. In the American case of Rodriguez v. State (1989), a 97 year old woman was attacked in her home and robbed, sustaining injuries during the knife attack, including visible scars. However, by the time the case reached trial she was 99 years old and had advanced Alzheimer's. There were inconsistencies and disconcerting statements from the victim, such as, she had never heard of Alzheimer's and she could only state her year of birth, not her age. On appeal, the defence claimed that her testimony should not have been allowed yet, the Court upheld her testimony. The Court stated, "If the appellant's conviction was based solely on 
Mrs. Pope's account of events, it might be more a cause for concern. But ... her testimony was used solely for proving the corpus delicti” (Rodrigues v. State, 1989). In other words, her testimony was allowed under the restriction that it provided proof that the crime occurred, but could not be used for other purposes (e.g., identification of the offender). Had there been no other witnesses, then likely the assault and robbery would have gone unpunished. Therefore, it stands to reason that the way elderly individuals are perceived in court is of concern, especially whether these perceptions are based on stereotypes, rather than ability, that may impact the verdicts rendered. To understand the issues as they relate to the elderly, age stereotypes, and jurors' decisions, the present study will explore the issues of ageism, geriatric disease, and level of care.

\section{Ageism}

A stereotype is an over simplified and blanketing portrayal of any group of individuals (Lomax-Cook, 2001). It is often erroneous, resistant to modification, and unrepresentative of the realities of the group and can be positive or negative (LomaxCook, 2001). When older adults (65 years and older) are stereotyped, earlier research has found that they tend to be perceived as fitting negative stereotypes such as senile, rigid in thought and manner, and old-fashioned in morality and skills (Butler, 1975). However, more recent research indicates that positive stereotypes also exist, such as being perceived as warm, nurturing, and living the good life like the 'cookie baking grandmother' and the 'golden agers' (Barrett \& Cantwell, 2007; Hummert, Shaner, Garstka, \& Henry, 1998).

The concept of age stereotypes has only been addressed by research with any consistency since the very late 1960s. In the 1920s and 1930s, the first evidence of age discrimination 
was noted in workplaces in Britain and the U.S.A.; however, it was not until 1969 that Robert Butler first coined the term ageism while chair of a program to rehouse older adults in the District of Columbia (Butler, 1969; Macnicol, 2006). Butler's (1975) evolving definition and work was focused on the "helping professions" but has since been broadened to apply to all forms of discrimination against the elderly. Ageism refers to prejudicial attitude or discriminatory action against older individuals based on age stereotypes (Butler, 1975). Prejudice can be negative such as believing older adults are less physically fit, or positive, believing that older adults are excellent storytellers. Discrimination can be negative such as refusing an older adult a job or positive such as cutting an older adult's lawn due to viewing them as incapable. In recent years, the definition of ageism has been broadened to include discrimination against young people, as well as older adults. Age discrimination has become a greater issue in the new millennium as individuals live longer. It is believed that at least part of the root of the negative stereotypes against older adults is the young's fear of becoming old (Macnicol, 2006). Macnicol (2006) suggests that both longer lives and a modern capitalist society have played strong roles in the decreasing social status of older adults. For example, older adults were once viewed as the pillar of wisdom and the cornerstone of society, but now are dismissed as being out of touch with today's technologically advanced society and are often the recipients of neglect. This decrease in social status is thought to be exacerbated by the decrease in economic status caused by the enforced idleness of retirement (Macnicol, 2006). Although often retirees are view as idle with copious amounts of time at their disposal, many retirees continue with some form of work, or fill their days with volunteering, social activities, or with extensive travelling. Therefore, understanding how 
stereotypes are formed is important to address social issues regarding aging in our society.

Stereotypes are formed using schemas. Schemas are an incorporation of a pattern with the accepted response, there are schemas associated with all aspects of our stereotypes (Sweller \& Cooper, 1985). Stereotypes are often described in negative terms as they can lead to discrimination; however, schemas play a crucial role in our ability to process information and remember details, although there may be errors based on our generalizations (Macie, Hamilton, Russkind, \& Rosselli, 1996). While schemas provide stereotypes for quick decision making, their primary purpose is conserving brain processes and freeing up working memory, these mental short-cuts, although time saving, can be erroneous.

How stereotypes are formed is addressed by many theories, each of which addressed a specific aspect of stereotypes or stereotypes against a specific group. The model this paper will consider first is social learning theory (Macie et al., 1996). Social learning theory suggests that a child's interpersonal interactions are the primary source of information about those in and out of their social group, the earliest and most potent source of this information is parents (Macie et al., 1996). Stereotypes are not intentionally transmitted but picked up by the child through observation (Mackie et al., 1996). When it comes to age stereotypes they develop early, children are well aware of age differences and able to accurately categorize people by age two (Edwards, 1984). This accuracy increases with age (up to age 5) and titles for the age groups because less familial in the older children's categorization (Edwards, 1984). For young children, age categorization and stereotypes are connected. Age stereotypes are based primarily on family members, 
specifically their stereotypes of older adults are based on their interactions with grandparents (or great-grandparents; Edwards, 1984; Pecchioni \& Croghan, 2002).

Another model which addresses the ways in which older adults are stereotyped by the in-group is the Fiske, Cuddy, Glick, and Xu (2002) stereotype content model, in an attempt to provide a systematic explanation for the nature of stereotypes, which often seem arbitrary. Their theory proposes that all stereotypes exist on two dimensions. The first is warmth, this is the extent to which the group is considered with warm feelings by the in-group. The second paradigm is competence. This is the extent to which they are viewed as competent by the in-group. Fiske et al. (2002) primarily define warmth in terms of lack of competition, so someone who is not competing for the in-group's resources. For example, jobs or admission to university would be viewed with high warmth. Those who are directly competing for resources are viewed with low warmth. Meanwhile competence is primarily defined by status in society. Those who are high status, for example those economically or educationally successful, compared with those who are low status and viewed as contributing minimally to society are rate higher in competence than those that do not (See Figure 1 for the model; Fiske et al., 2002).

Fiske et al.'s (2002) model can be extended to age stereotypes. To extrapolate, based on Fiske et al.'s (2002) model, our culture holds a paternalistic prejudice towards older adults. They are viewed with warmth but low competence due to the stereotype of older adults being 'nice and kind but forgetful'. This age prejudice leads to pity and sympathy being the primary cultural attitudes towards this group that includes individuals such as older adults, persons with disabilities, and housewives (Fiske et al., 2002). 
Figure 1 Four groups based on Fiske et al. (2002) function of perceived warmth and competence.

\begin{tabular}{|c|c|c|}
\hline & Comp & ence \\
\hline Warmth & Low & High \\
\hline \multirow{4}{*}{ High } & Paternalistic Prejudice & Admiration \\
\hline & Low status, not competitive & $\begin{array}{l}\text { High status, not } \\
\text { competitive }\end{array}$ \\
\hline & Pity, sympathy & Pride, admiration \\
\hline & $\begin{array}{l}\text { e.g. elderly people, person } \\
\text { with a disability } \\
\text {, housewives }\end{array}$ & e.g. in-group, close allies \\
\hline \multirow{4}{*}{ Low } & Contemptuous Prejudice & Envious Prejudice \\
\hline & Low status, competitive & High status, competitive \\
\hline & $\begin{array}{c}\text { Contempt, disgust, anger, } \\
\text { resentment }\end{array}$ & Envy, jealousy \\
\hline & $\begin{array}{l}\text { e.g. welfare recipients, poor } \\
\text { people }\end{array}$ & $\begin{array}{l}\text { e.g. Asians, Jews, rich } \\
\text { people, feminists }\end{array}$ \\
\hline
\end{tabular}

When applying Fiske et al.'s (2002) model to mock jurors' perceptions of older adults it would be expected that older adult eyewitnesses are viewed with high warmth. In other words, mock jurors' would be expected to have positive feelings towards the older adult witness, as a person. This is consistent with the findings, discussed later, that older adults are generally rated as more honest than their younger counterparts (Allison, 
Brimacombe, Hunter, \& Kadlec, 2006). As for competence, according to Fiske and colleagues (2002) older adults are viewed as having low competence. For an older adult eyewitness this could mean that their testimony could be dismissed. This is consistent with the finding that older adults are generally viewed as less accurate and competent than younger eyewitnesses (Brimacombe, Quinton, Nance, \& Garrioch, 1997).

To examine how stereotypes of age are expressed in the general population, Hummert (1990) conducted a series of studies asking individuals from a variety of age groups to assess which stereotypes were most common and what age group they best applied. Hummert (1990) found that young adults (undergraduate students) rated the negative stereotype of older adults (i.e., inflexible senior citizens) as more common and rated them as being most typical of adults 75 years or older. He also found that young adults created a broader range of stereotypical groups for themselves than they did for older adults, meaning they viewed older adults as more homogeneous than themselves (Hummert, 1990). This study was followed up, comparing multiple age groups: young adults ( 18 to 22 years, $M_{\text {age }}=19.7$ years), middle aged adults ( 35 to 51 years, $M_{\text {age }}=$ 40.5), and elderly adults (60 to 80 years, $M_{a g e}=70.9$ years; Hummert, Garstka, Shaner, \& Strahm, 1994). Each of the three age groups was asked to provide as many stereotypes of elderly adults as they could. Elderly adults produced the shortest list of stereotypes and their list tended to have fewer traits and yet more groupings of stereotypes than those of their younger counterparts (Hummert et al., 1994). Hummert et al. (1994) found that although all adults have similar stereotypes of the elderly, the middle aged and elderly adults' stereotypes are more complex than those of young adults. The stereotypes are more complex in that older adults provide more adjectives or descriptors per adjective. 
They replicated this study using multiple age groups as comparisons: young adults ( $M_{\text {age }}$ $=21.2$ years $),$ middle-aged adults $\left(M_{\text {age }}=45.0\right.$ year $)$, and elderly adults $\left(M_{\text {age }}=72.7\right.$ years; Hummert, Garstka, Shaner, \& Strahm, 1995). They found similar results to the 1994 study but also found that regardless of the age of the rater, the most negatively rated stereotypes, such as 'severely impaired', were associated with older ages than the most positive stereotypes, such as the 'perfect grandparent' (Hummert et al., 1995). Though rating the positive stereotypes as younger than the negative ones was consistent across age, elderly adults rated them as older than did younger adults and middle aged adults (Hummert et al., 1995). Thus, the younger a person is, the sooner they imagine that the negative effects of aging take hold, whereas when you get closer to old age you see less of the negative stereotypes, such as senility, in yourself or peers. Therefore, you feel that it must be at an older age that these negative effects begin. This effect was reversed for the negative stereotype of 'vulnerability', where younger adults rated the typical age at which they believe a person becomes vulnerable as significantly older than did the elderly adults (Hummert et al., 1995). In this case, older people see themselves as becoming vulnerable before a younger person would imagine this state would take hold. When it comes to vulnerability, age of the rater explained $17 \%$ of the variance of age judgment (Hummert et al., 1995). This line of research was continued by Davis and Friedrich (2010), who compared the stereotypes of older people provided by individuals between 40 and 99 years of age. They found that the youngest adults (40 to 49 years) and the oldest adults ( 85 to 99 years) hold the most negative biases about aging. They also found that, regardless of age, the lower life satisfaction an individual feels, the more negative stereotypes they will hold (Davis \& Friedrich, 2010). In other words, the less 
satisfied a person is with their life, the more likely they are to hold a greater number of negative stereotypes. The authors differentiated between physical, psychological, and social domains of aging and found that the most negative stereotypes are centered around the physical effects of aging, with the older participants holding the most negative physical stereotypes (Davis \& Friedrich, 2010). It was postulated that some of these differences in stereotypes may be influenced by media, in that the younger participants have been exposed to more media, especially as children, than the older participants (as the oldest adults in this study were born in 1910 and the youngest in 1965; Davis \& Friedrich, 2010).

The effect of media on ageism suggested by Davis and Friedrich (2010) has received much attention in the area of advertising. The effect of media on stereotypes is especially important as we grow older, those early stereotypes from our parents and interactions with grandparents are reinforced or informed by later experiences, which for many come through the media (Davis \& Friedrich, 2010; Edwards, 1984; Pecchioni \& Croghan, 2002). When older adults are portrayed in advertising, older adults (56 to 75 years) and college students (18 to 25 years) tend to perceive the older adults in the advertisements in similar ways and believe that portraying negative stereotypes of the elderly has an overall negative effect on society (Robinson, Gustafson, \& Popovich, 2008). The older adults preferred advertisements that showed them in a positive manner, such as clever, regardless of whether stereotypes were used (Robinson et al., 2008). Older adults found it most offensive when they were portrayed as searching for "lost youth", such as playing a "rock guitar"; whereas, younger adults were more concerned when older adults were portrayed as unattractive or "out of touch" with the world (Robinson et 
al., 2008). Not only do the ways older adults are portrayed in advertisements conform to stereotypes, but individuals' interpretation of how effective advertisements are is influenced by stereotypes. Advertisements conform to both positive and negative stereotypes. For example, a positively stereotyped commercial might portray an older woman as a kind, cookie-baking grandmother to sell flour. In contrast, to sell a chair lift to older adults, advertisements would portray the elderly as weak and frail. Umphrey and Robinson (2007) found that college students (17 to 37 years, $M_{\text {age }}=20$ ) used negative stereotypes of older adults (40 and 70 years) to interpret how influential an advertisement would be. For example, students believed that a Lincoln (car company) advertisement would have a great deal of influence on a 40 year old but less so on a 70 year old. These results suggests that college students believe, based on their stereotypes, that people in their 70's drive less, are less interested in cars, and potentially do not have the financial means to purchase a vehicle (Umphrey \& Robinson, 2007). When the media portrays stereotypes, it elicits an acceptance in society, in that, society accepts the portrayals of people as factual renditions and adopts the stereotypes as true.

Acceptance of stereotypes may lead to people behaving differently towards older adults. The early research by Hummert and colleagues was limited to the nature of the stereotypes that exist in an individual's thoughts and could not assess effects of the stereotypes. A later study (Hummert et al., 1998) looked at the effect of stereotypes on the tone of voice and communication styles used with older adults. Two 'personas' were created, one which fit the negative stereotype of a despondent older adult, the other fitting the positive stereotype of the golden ager. Participants were presented with an image and list of traits for each persona. Young adults ( 18 to 27 years, $M_{\text {age }}=20.03$ years), middle 
aged adults ( 35 to 52 years, $M_{\text {age }}=41.83$ years), and elderly adults (64 to 94 years, $M_{a g e}=$ 77.05 years) rated how they believed their voice would sound when speaking to the elderly adult persona (e.g., speed, expressiveness, and volume; Hummert et al., 1998). Participants then were presented with a scenario where they had to persuade the persona to do something (Hummert et al., 1998). The results showed that when presented with a 'despondent' persona, all ages used slower speech and were more expressive. This effect was stronger for younger and middle aged adults, whose speech patterns were significantly more patronizing than when the persona presented was a 'golden ager' (a person who is aging normally, active, and enjoying retirement; Hummert et al., 1998). This exemplifies the way that these stereotypes can influence peoples' interactions with older adults. The same stereotypes can be expressed in subtle ways. Barrett and Cantwell (2007) asked young adults (undergraduate students) to draw an image of an elderly person. They found that when more aged characteristics were present (e.g., physical aids or balding/thinning hair), the drawing was smiling significantly less often, this pattern followed for drawings with wrinkles but was non-significant (Barrett \& Cantwell, 2007). The drawings generally conformed to negative stereotypes such as impairment and isolation; however, a small group provided more positive stereotypes, especially of women, as kind and cookie-baking grandmothers (Barrett \& Cantwell, 2007). Although participants in the current study will not actually be interacting with older adults, much like in the Hummert et al. (1998) study they will be imagining the witness based on the information provided in the transcript. Therefore, it is important to recognise the impact that stereotypes may have on people's behaviour and the ways they can influence those with whom they interact. 
The majority of research addressing ageism, specifically related to older adults, focuses on the negative stereotypes. Part of the reason for this is likely that in day to day life when people experience ageism it is generally only the negative experiences that cause problems. If someone holds a door for an older adult, although plausibly due to ageist beliefs, it is not viewed as a problem. On the other hand, if a sales person is upselling an older adult it is viewed as an abuse of the kindly and vulnerable older adult. For example, selling them expensive or unnecessary upgrades and accessories, because the salesperson believed they have no knowledge of technology. Alternatively, participants may think of stereotypes as having a negative connotation; therefore, more report the negative stereotypes. It is also possible that the greater reporting of negative stereotypes towards older adults is representative of the proportions of stereotypes that exist.

Ageism continues to be prevalent today and those who perceive or experience more discrimination based on their age had earlier mortality than those who perceive or experience less discrimination (Barnes et al., 2008). Palmore (2001) found that nearly $80 \%$ of his sample of people 60 years and over reported experiencing at least one incidence of ageism and more than half of those reported the incident to have occurred more than once (Palmore, 2001). A further 20\% reported the ageism as coming from more than one person (Palmore, 2011). The most common forms of ageism found by the study were 'being poked fun at', 'being ignored', or 'not taken seriously' (Palmore, 2001). Individuals over 75 reported more events of ageism than those under 75 (Palmore, 2001). Women also reported more ageism. Palmore (2001) postulated this was because they recognise discrimination when it occurs from having experienced sexism. With 
Ageism so salient in our society, it is important for the legal system to understand how it influences juror decision-making. In a juror decision making context, jurors may use schemas to reach conclusions. That is, jurors may take short cuts in remembering the information presented by using their existing schemas to make quick decisions and remember trial facts. These quick decisions include interpretations of the veracity of testimony: is the witness credible, competent, and telling the truth. The term elderly has, to a great extent, become synonymous with disability (Quinn \& Tomita, 1997).

Therefore, the perceived confirmation of disability for a juror, through learning that a witness is old, unable to live independently, or has a geriatric disease, may influence juror decision-making. The present study will include a manipulation of age of the eyewitness to examine the influence of stereotypes of older adults held by jurors.

\section{Age of Eyewitness}

\subsection{The Elderly}

Jurors consider a variety of witness characteristics when evaluating testimony, such as age, gender, race, and developmental/cognitive status (Eaton, Ball, \& O’Callaghan, 2001). Older people may experience victimization or witness crime; as such, it is important for us to understand jurors' perceptions of the older eyewitness and factors that may impact it. Canada's senior population (aged 55 and older) is one of the fastest growing populations in the country (Statistics Canada, 2010). In the coming decades, Canada's senior population will continue to grow, rising from $27 \%$ in 2011 to 35\% in 2031 (Statistics Canada, 2010). Statistics Canada (2010) estimates that by 2031 approximately $7 \%$ of the total Canadian population will be over 80 years of age. This phenomenon is not limited to Canada. The United Nations estimates that the number of 
older people in the world will triple between 2009 and 2050 (Moriya, Tei, Miura, Inoue, \& Yokoyama, 2013). As the number of older adults in society rises, it is expected that the number of crimes against them will too.

Though rates of elder victimization tend to be low, they are expected to rise as the greater portion of our population falls into that category (Carrington, 2001; Shock, 1985; Statistics Canada, 2012). Some research has suggested that rates of elder victimization are as low as $10 \%$ for those over 65 compared to $31 \%$ for those under 65 (Ogrodnik, 2007). A study of a large group of older adults in Connecticut, U.S.A., found that in their cohort, $29 \%$ of older adults had non-medical interactions with the police (Lachs et al., 2003; Lachs et al., 2004). Of those, $62.1 \%$ interacted with the police as the victim of a crime, of which $21 \%$ of the crimes were violent, primarily assault and robbery (Lachs et al., 2003; Lachs et al., 2004). Of the remaining non-violent crimes, older adults were most likely to experience larceny (theft without force) and burglary (theft from a home; Lachs et al., 2003; Lachs et al., 2004). Victims of crime were most likely to have little to no functional or cognitive impairment. This defies the stereotypical frail and confused senior as the victim. Although stereotypes often present older women as the victim of crime, there was no effect of gender, once functionality and social interactions were controlled (Lachs et al., 2003; Lachs et al., 2004). Of the total number of victimizations, only $4.6 \%$ occurred in a nursing home; however, of the total number of violent assaults, almost $25 \%$ occurred in a nursing home and the majority of these were resident-onresident assaults (Lachs et al., 2003; Lachs et al., 2004). There was a further $4.1 \%$ of the cohort who witnessed a crime, meaning that in total more than $65 \%$ of older adults in this Connecticut cohort could have been called to testify in court (Lachs et al., 2003; Lachs et 
al., 2004). A study of the patterns of crime from 1992 through 1994 revealed that for individuals 65 and older in the United States, though experiencing much less crime than their younger counterparts, were far more likely to sustain an injury (Bachman, Dillaway, $\&$ Lachs, 1998). Further to that, older adults were more likely to require medical attention for injuries sustained in a robbery or assault (Bachman et al., 1998). Once over 65 years, men and women are at virtually equivalent risk of being robbed (Bachman et al., 1998). Older adults also were far more likely to be victimized by a stranger compared with younger individuals (Bachman et al., 1998).

In light of the rates of victimization, some consideration must be made for how older adults are viewed in the courtroom. Many countries including Canada, England, and Wales have laws which include special measures to protect vulnerable individuals when testifying (Bala, Paetsch, Bertrand, Thomas, 2011; Hall, 2007). When the Canadian laws were instituted in 1988, they pertained exclusively to the protection of child witnesses (Bala et al., 2011). The laws were updated in 2006 in Canada and 1998 in England and Wales to include vulnerable adults (Bala et al., 2011; Hall, 2007). Under the British laws a vulnerable adult may include someone with a disability, mental, or physical disorder; this definition could often include older adults and certainly those with geriatric diagnoses (Hall, 2007). Despite these changes to the law, there is heavy focus in research and in the use of these provisions with children (under 18 years of age; Bala et al., 2011; Hall, 2007). For example, one provision under Canadian law is the presence of a support person, when judges were surveyed in cases involving children they had all at least occasionally submitted an application, compared to in vulnerable adults where 11 out of 17 judges had never made an application for a support person (Bala et al., 2011). 
The patterns were similar for closed circuit television and video-recording evidence (Bala et al., 2011). Although, the applications for both children and adults were often unsuccessful, if applications for vulnerable adults are never made they cannot be successful (Bala et al., 2011). These special measures are meant to be use by judges to facilitate vulnerable persons providing evidence in court to give better, clearer testimony as the processes of the courtroom can be very daunting for them (Hall, 2007). Better institution of these special measures may allow older adults to better participate in the judicial process.

\subsection{Accuracy of older adults}

There has been more research of the accuracy of older adults as eyewitness, than on jurors' perceptions of older adults' accuracy. Witnesses are often asked to identify the criminal from a lineup. Wilcock, Bull, and Vrij (2005) looked at eyewitnesses' accuracy in picking the criminal out of a lineup. They found that older adults (62 to 83 years) had decreased lineup performance when compared to their younger (18 to 31 years) counterparts. A follow up study found that this difference could be reduced by using adapted lineup procedures, such as including a practice target-absent lineup (i.e., the witness is presented with a lineup of people known to be innocent before experiencing the lineup including the suspect; Wilcock \& Bull, 2010).

When older adults (57 to 83 years) were compared to younger adults (19 to 33 years), only the older adults were influenced by hearing post-event verbal information such as another witness's account or a media report (Searcy, Bartlett, \& Memon, 2000). They also found that the older adults, who demonstrated high levels of verbal recall of the criminal and event, were more likely to make a false positive identification (Searcy et al., 
2000). Research has shown that when older adults are presented with misinformation, they are more likely to take the false information they received and include that as part of what they recall subsequently compared to college students (Mitchell, Johnson, \& Mather, 2003). This is believed to be in part the result of a source misattribution, meaning that they remember the information but cannot remember where it came from (Mitchell et al., 2003). Mitchell et al. (2003) found that older adults $\left(M_{\text {age }}=76.0\right.$ years, $S D=3.8$ years) were more susceptible to misinformation than younger adults $\left(M_{\text {age }}=19.6\right.$ years, $S D=1.5$ years). They also found that older adults were more likely to rate themselves as having more confidence in their recall, when compared with younger adults, and older adults were less confident when attempting to attribute their memories to a specific source (Mitchell et al., 2003). Dodson and Krueger (2006) similarly found that older adults were more susceptible to misinformation errors; i.e. incorporating inaccurate details into their own recall. What is most concerning with the misinformation errors is that older adults continued to rate their confidence high while they are making the errors (Dodson \& Krueger, 2006). The extent to which older adults are able to give accurate testimony is an important issue because jurors' perceptions of older adults' competence (e.g. bias of perceiving older adults as less competent) may impact their perception of the clarity of the actual testimony. These jurors' misconceptions could lead to errors in decision making by jurors should their perception of older adults testimony and the older adults actual accuracy not line up.

Given jurors, do not know whether the information they are hearing is accurate, they rely on the way witnesses present the story as part of their assessment of reliability. As older adults often present their testimony differently than younger adults it is an 
important consideration in understanding jurors' perception of them. List (1986)

compared children (10 years of age), younger adults $\left(M_{\text {age }}=20.1\right.$ years $)$, and older adults $\left(M_{\text {age }}=72.3\right.$ years $)$, and found that older adults gave less complete accounts of a crime than younger adults, but were no less accurate. There was an interaction found between the age of the witness and age of the actress portraying the crime. In this study, videos were made of an actress (college student versus middle aged) shoplifting to test eyewitness accuracy. Older adults gave more accurate and complete descriptions of the actions and person-characteristics of the older actress, and their memory of the older actress was as good as the younger adults' memories for both actresses (List, 1986). When assessing a witnesses' reliance on a script, meaning the sequence of events that would be expected to occur, such as what ought to happen during a bank robbery, research has found that older adults are more reliant on scripts (Garcia-Bajos, Migueles, \& Aizpurua, 2012). Garcia-Bajos et al. (2012) found that older adults (57 to 73 years) and younger adults (19 to 27 years) had no significant difference in recall of highly typical events, such as demands for cash or people screaming. However, the younger adults were more accurate at recalling the low typicality events, such as 'tell people to be quiet' or 'assisting an injured person' (Garcia-Bajos et al., 2012). Older adults also were found to have a higher rate of false positives in a recognition task, where participants were shown images and asked if they occurred in the crime 'witnessed' (Garcia-Bajos et al., 2012). In general, older adults have been found to have more inconsistent accuracy than their younger counterparts, especially when faced with additional challenges (misinformation, post-event information, or low typicality events). However, Mello and Fisher (1996) found no effect of age in their study comparing older ( $M_{\text {age }}=71.73$ years $)$ and younger 
witnesses $\left(M_{\text {age }}=21.60\right.$ years $)$. Nevertheless, there is more to jurors' perceptions of older adults than simply their accuracy.

\subsection{Jurors' perceptions of the elderly}

When narrative features (i.e., the way the evidence is presented) were compared, older adults $\left(M_{\text {age }}=75.63\right.$ years $)$ were more likely to tell a story (i.e., interconnecting the events to provide flow as opposed to listing events) than younger adults ( $M_{\text {age }}=19.68$ years; Allison et al., 2006). Older adults interjected themselves into the testimony by means of commenting on character and providing opinion (Allison et al., 2006). Older adults also were more dramatic in their telling of the crime and more likely to insert past experiences, whereas younger adults were more likely to give highly structured testimonies that had a clear sequence of events, few elaborations, and little conjecture (Allison et al., 2006). Allison and colleagues also found that older witnesses were generally perceived as being more honest than their younger counterparts. However, regardless of age, witnesses were perceived as most competent when using sequencing in their testimonies. In other words, providing the listener with temporal and/or logical connections for the progression of events in the testimony increased jurors' perceptions of competency of the witness (Allison et al., 2006). The manner in which older adults retell events (e.g. meandering) may trigger stereotypes of older adults being less competent in their testimony when in fact the information may be just as accurate. The transcript used in the current study will be written to exemplify many of the traits found above.

Limited research has been conducted assessing jurors' perceptions of older adults as accurate eyewitnesses. Brimacombe and colleagues (1997) compared three age groups of eyewitnesses; the young (18 to 25 years) and middle aged groups (30 to 44 years) were 
compared to an older group (65 to 85 years). Mock jurors were asked to assess the videotaped eyewitness testimonies of these three groups for the perceived credibility of the witness. The results indicated that older adults were perceived as less cognitively able by jurors. However, this was confounded by the fact that the older adults' participation in an earlier portion of the study had indeed performed worse at remembering the crime details (Brimacombe et al., 1997). They found that generally, older eyewitnesses were perceived as more honest than the middle aged group and equally honest as the young group, but less accurate, competent, confident, and credible than either of their younger counterparts (Brimacombe et al., 1997). This research was followed up by a similar study where rather than having a middle aged group, a young group (18 to 30 years) was compared to a younger senior (59 to 74 years) and older senior group ( 75 to 88 years; Brimacombe, Jung, Garrioch, \& Allison, 2003). In contrast to the Brimacombe et al. (1997) results, this study found that although the older seniors were significantly less accurate than the two comparison groups, the mock jurors did not perceive them as less accurate than the younger adults (Brimacombe et al., 2003). Mock jurors also rated all age groups as equally credible (Brimacombe et al., 2003). In a study by Kwong See, Hoffman, and Wood (2001) that compared jurors' perceptions of a younger (28 years of age) and an older ( 82 years of age) female eyewitness, it was found that the older witnesses' reliability was compromised by a lack of believability. Specifically, the stronger a mock juror stereotyped older adult as incompetent or unbelievable, the less likely jurors were to rate them as reliable (Kwong See et al., 2001). Kwong See et al. (2001) also found a significant negative correlation between eyewitness age and competence ratings. 
Much of the above research looking at jurors' perceptions of elderly eyewitnesses has focused on transcripts taken from interviews with older adults acting as mock eyewitnesses. This method, though ecologically valid, does not allow assessment of how much a juror's bias (i.e. stereotypes) or preconceived notions of elderly people influence their ratings of reliability because there are other variables, which are not held constant, such as style of testimony. Using a mock transcript will allow more direct assessment of this bias because all aspects of the testimony other than the eyewitness's age and other independent variables will be held constant.

A study by Neal, Christiansen, Bornstein, and Robicheaux (2012) used mock transcripts to examine the number of guilty verdicts provided by mock jurors when the main eyewitness was a child (6 years), versus youth (11 years), versus adult (42 years), versus elderly adult (74 years). They found that eyewitness age significantly interacted with the verdict, defendant culpability (the extent of guilt [out of 100]), and eyewitness credibility ratings, where the elderly and the child were most likely to elicit not guilty verdicts, lower defendant culpability, and were rated as less credible compared with the adult (Neal et al., 2012). In an attempt to flesh out the effects of jurors' perceptions of an older victim or witness on their verdict choice and credibility ratings, Nunez, McCoy, Clark, \& Shaw (1999) created five different personas for analytic comparison: generic adult victim (31 years), generic elder witness (66 years), vulnerable senior citizen (66 years), grandfather (66 years), and statesman (66 years). Nunez et al. (1999) asked undergraduate students ( 18 to 49 years, $M_{\text {age }}=21.51$ ) and a community sample (19 to 91 years, $\left.M_{\text {age }}=39.15\right)$ to read transcripts presenting one of these five personas and to render verdicts in the case. Interestingly, they found no difference between the verdicts of 
the students and the community sample, nor any difference in believability ratings between the personas (Nunez et al., 1999). However, there was a difference in the verdicts rendered for the different personas where the statesman was awarded more guilty verdicts than the generic adult, vulnerable senior, or the grandfather (Nunez et al., 1999). It also was found that the senior who was presented as being vulnerable received fewer guilty verdicts than the generic senior (Nunez et al., 1999).

The findings of the above studies demonstrate that the way individuals perceive older adults is different from younger and middle aged adults. Research has demonstrated that this perception of the older adults begins even before the witness ever makes it to the stand. Wright and Holliday (2005) administered a survey asking police officers about their experiences with older witnesses. They found that the majority of police officers were less confident in elderly witnesses and had concerns about their reliability and thoroughness in recalling the incident (Wright \& Holliday, 2005).

These differences in the way older adults are perceived and treated extend beyond the criminal justice system. For example, Kwong See and Heller (2004) asked adults (18 to 38 years) to judge cartoon submissions which they were told came from a young (21 years), young-old (65 years), or old-old adult (81 years). When raters were presented with a badly drawn cartoon, the young-old adults were rated most harshly with the young and old-old adult being rated more leniently (Kwong See \& Heller, 2004). Conversely, when the cartoon was well drawn, the young-old group was rated most favorably with the young and the old-old being rated as less successful. This suggests that the raters' expectations and assessment criteria change based on the performer. They did not expect the old-old group to do well; therefore, when they performed poorly they are not rated 
harshly because low performance was expected and when they perform well it is rated as "very good for old-old persons" (Kwong See \& Heller, 2004, p. 71) and old-old adults receive less credit for success than their younger peers.

The exact age at which the influence of ageism on perception of jurors and their verdicts occurs is not clear. However, when the age range is too small that is being studied, there is no effect. When comparing the testimony of older adults, aged 66,76 , or 86 years of age, researchers found that there was no effect of age on verdict or ratings of credibility (Golding, Yozwiak, Kinstle, \& Marsil, 2005). This indicates that mock jurors do not significantly differentiate between a witness of 66 years of age and one of 86 years of age. Therefore, a greater age range is necessary to determine if there is a significant effect.

The witness' knowledge and experience with stereotypes and ageism could influence their basic ability to perform in court and by extension their perceived credibility. Ageism and stereotypes may influence older adults beyond any effect of age on accuracy. Regardless of age, the courtroom experience is, for most people, highly stressed and full of unknowns (Hirschel \& Rubin, 1982). These anxieties can be heightened for elderly members when they fear that jurors will automatically doubt their credibility because of stereotypic perceptions of their weakening eyesight, hearing, memory, etc. (Hirschel \& Rubin, 1982). With older eyewitnesses being more susceptible to suggestion and less sure of themselves, their uncertainties may be palpable among the jurors, further denigrating their credibility as witnesses (Dodson \& Krueger, 2006; Hirschel \& Rubin, 1982; Mitchell et al., 2003). In an attempt to better understand the extent to understand jurors' perceptions of the elderly, the present study will use mock 
trial transcripts where the age of the eyewitness is manipulated; 45 years vs. 65 years vs. 85 years. The variable of witness age is key to understanding whether older adults are treated differently than younger adults, the choice to look at $45,65,85$ is based on two factors. First, in earlier studies which used only ten-year gaps there was no significant effect of age (66, 76, 86; Golding et al., 2005) and second, no younger age group (25 years) was used in order to control sample size, avoiding trying to collect an unrealistically large sample. This is, broadly speaking, the same age group that has been focused on in previous studies; therefore, this study will serve as a further assessment of the effect of age.

\section{Geriatric Disease}

Geriatric disease is a broad terminology that refers to disorders influencing older adults, that deviates from the normal aging process (Colman, 2008). For example, it is normal to lose some memory as you age; however, forgetting your loved ones is an extreme loss of memory and may be symptomatic of a geriatric disease such as Alzheimer's. Alzheimer's is a specific type of dementia, "it is a progressive, degenerative, and fatal brain disease" (Alzheimer's Society of Canada, 2010, p. 10). The witness in the present study will state that they have "early stage dementia." Dementia is a broad term, which encompasses many disorders and many clinical manifestations, including Alzheimer's (Alzheimer's Society of Canada, 2010). The specification of Alzheimer's is generally considered more severe, as Alzheimer's, unlike other dementias, has no treatment, no chance of recovery, and once diagnosed patients generally die within seven to ten years, during which the patient will suffer an often swift loss of memory and function (Alzheimer's Society of Canada, 2010). Dementia was chosen as the diagnosis 
in this study because it tends to be less severe than Alzheimer's, yet has a high prevalence (Alzheimer's Society of Canada, 2010). According to the Diagnostic and Statistics Manual fifth edition (American Psychiatric Association, 2013), the prevalence of dementia ranges from 2 to $10 \%$ at age 65 and has been estimated as high as $30 \%$ by age 85 years. The Alzheimer's Society of Canada (2010) estimates that by 2038 these numbers will have risen to $50 \%$ of those over the age of 90 .

Only a couple of mock juror studies (Golding, Allen, Yozwiak, Marsil, \& Kinstle, 2004; Kinstle, Hodell, \& Golding, 2008) have considered the effect of a cognitive impairment on verdicts rendered and it seems that none of the previous research has chosen to give the witness a specific geriatric disease. Previous research has found that when using mock transcripts that included a victim described as having a cognitive deficit, more not guilty verdicts were elicited from mock jurors than a victim described as having a physical disability (Golding et al., 2004). A follow up study, describing a victim as healthy, confused, or frail, found no direct effect on verdicts; however, jurors felt less confident in not guilty verdicts when a victim was confused (Kinstle et al., 2008). The use of a geriatric disease as well as level of care as independent variables is highly appropriate and important to examine since the rates of mental and behavioural disorders in nursing homes has been estimated to be between 60 to $90 \%$ (depending on research methodology; Podgorski, Tariot, Blazina, Cox, \& Leibovici, 1996).

By creating an eyewitness with a geriatric disease, it will be possible to assess the extent to which the individual's cognitive status is recognised and considered by the mock jurors. However, in order to differentiate between the dramatic effect of medical buzz terms for geriatric diseases such as dementia, delirium, or Alzheimer's, and the 
decrease in cognitive ability associated with these diseases, the eyewitness will also identify themselves either as living in a long-term care facility or as living at home in the community (Colman, 2008). The use of the variable geriatric diagnosis is not previously addressed in the literature. The closest descriptor variables used to geriatric diagnosis are confused, frail, and cognitive defect. The addition of the geriatric diagnosis as a variable will allow for assessment of mock jurors' perceptions of age when combined with factors that knowingly effects recall memory, which are related to aging. This will add another aspect of the complications associated with elderly eyewitnesses to the literature.

\section{Level of Care}

As people age, caring for themselves in their own home becomes more difficult. There are many things that may happen to someone living independently at home, that could force them to leave, such as, injury, illness, bereavement, financial issues, etc. Research has found a connection between victimization by crime and residing in a longterm care facility (Lachs et al., 2006). They found that although not statistically significant, there was a positive relationship between moving into a long-term care facility and being victimized, being victimized by a stranger, and sustaining injury in the encounter (Lachs et al., 2006). However, there was a positive and statistically significant relationship between experiencing a violent offence and moving to a long-term care facility within the follow-up period (Lachs et al., 2006). This effect was strong enough to remain present even once other medical and psychosocial variables were controlled for; where individuals who had experienced a violent offence were more than twice as likely to live in a long-term care facility at the end of the 10 year follow up period (Lachs et al., 2006). In many cases, the time elapsed between a crime and the end of a trial can be 
significant. In Canada in 2011/2012, the median length of all court cases was 117 days once the trial started, for homicide cases this increased to 386 days (Boyce, 2013). When you add those days to the expected time between the filing of charges or arrest and the first day of trial a total of eight to ten months will likely have passed (Boyce, 2013), many elderly victims may have already moved into a long-term care facility by the time it is their turn to testify (Boyce, 2013). Therefore, it is important for us to know how the knowledge that a witness lives in a long-term care facility will influence the perception of jurors.

Of the nearly five million seniors aged 65 plus in Canada, almost $8 \%$ live in some type of collective dwelling, such as a residence for senior citizens, nursing home, hospice, or hospital. These numbers are greatest for people over 85 , where over $40 \%$ of people in their nineties and almost $70 \%$ of centenarians live in collective dwellings (Statistics Canada, 2012). The majority of the $8 \%$ of seniors living in collective dwellings live in a specialized care facility (Statistics Canada, 2012). A collective dwelling denotes any place where multiple individuals or family units live separately but under one roof, whether long or short term (adapted from Statistics Canada, 2007). This can include places such as hotels, hospitals, retirement homes, jails, or military bases. I will focus on the facilities which provide specialized care because they service a clientele who cannot care for themselves, they tend to be older, and are more likely to have geriatric diagnoses all of which play into stereotypes of older adults that mock jurors may have. Specialized care facilities in Ontario have three main levels of care: the lowest is assisted living services, where older adults still live at home and are visited by services such as nurses and housekeeping. This allows them to remain at home with some independence but 
having their needs met. The second is a retirement home, where older adults can live independently but have services like meals, activities, and housekeeping provided for them. However, individuals living in retirement homes require little to no nursing care and do not have their freedom restricted. The highest level of care are long-term care facilities, where all meals, housekeeping, and group activities are provided, as well as 24 hour nursing care and medications are dispensed for the individuals. This paper will not include complex continuing care, where the individual is entirely incapable of any personal care such as feeding, bathing, and using the bathroom. This study will use the term long-term care facility to refer to the living arraignments of the witness; this is to avoid the imagery of social events and casino field trips that is sometimes associated with nursing homes. By the current study focusing on long-term care facilities instead of retirement homes, it will give the witness a seemingly more serious illness or a greater requirement for an advanced level of care.

The inclusion of level of care as a variable is based on the increasing incidence of crime and abuse in nursing homes and other long-term care facilities and the increasing population in these facilities as society continues to age. The conservative estimates of abuse cases in Canadian long-term care facilities in 2011 are approximately 24,000 (Hitzig et al., 2013). There are three types of abuse that can occur in a long-term care facility: caregiver/staff-on-resident, resident-on-caregiver/staff, and resident-on-resident. The caregiver as the aggressor has been the focus of most concern and research (McDonald et al., 2015); however, this is perhaps misguided. Estimates of rates of occurrences vary widely depending on methodology. One study found that more than $33 \%$ of caregivers had witnessed and that $10 \%$ of caregivers had been perpetrators in the 
preceding year (Crumb \& Jennings, 1998). Another study estimated that between 81 and $91 \%$ of nurses or nurses aids had either seen or heard about abuse in the previous year (Mercer, Heacock, \& Beck, 1993). When a resident aggresses against a caregiver there tends to be fewer repercussions. It has been estimated that $20 \%$ of nursing assistants experience physical violence on a daily basis (Astrom, Bucht, Eisemann, Norberg, \& Saveman, 2002). Only recently have researchers become interested in resident-onresident abuse, it has been estimated that resident-on-resident abuse represents between 28 and $60 \%$ of all incidences, that occurs in the long-term care facilities (Hitzig et al., 2013; Lapuk, 2007, as referenced in McDonald et al., 2015; McDondald et al., 2015; Wood, 2007, as referenced in McDonald et al., 2015). When it comes to injuries sustained as a result of resident-on-resident abuse, approximately $13 \%$ were fractures and the majority were bruises or lacerations (74\%; Shinoda-Tagawa et al., 2004).

With these three types of abuse combined there is much reason to be concerned about how jurors will perceive a resident of a long-term care facility. The inclusion of the level of care variable is also important because the chances of a witness ending up in a long-term care facility between the date of the crime and the date of the trial are far higher than for individuals who have not been the victim of crime. Any bias on the part of jurors held towards the elderly would likely be exacerbated by the existence of a further debilitating factor such as a geriatric disease. Most adults living in supportive care environments have a condition that decreases their ability to care for themselves in the community.

Hodell et al. (2009) also compared the nature of the verdicts when the sexual assault of an elder occurred in a nursing home versus the individual's private home, and 
found that mock jurors were more inclined to render a guilty verdict when the assault occurred in a private home rather than a nursing home. Similar to the results found by Golding et al. (2005), Hodell et al. (2009) found that when using a smaller range of ages $66,76,86$ years, age had no influence on verdict; however, it is worth noting that the majority of verdicts rendered were not guilty (67\%; Hodell et al., 2009). Interestingly, mock jurors provided higher ratings of victim believability and memory recall when the accused was a nursing home attendant rather than the victim's son. However, when the nursing home attendant was accused, there was no significant difference in guilty verdicts between those occurring in a nursing home and those occurring at the victim's private home (Hodell et al., 2009). Therefore, level of care along with other factors can influence jurors' perceptions of a crime and, by extension, their verdicts.

As the population ages, the number of people living in facilities will also increase, making it crucial to understand how jurors will perceive a witness who is living in a longterm care facility and by extension, their cognitive status. The cognitive status of an individual for the purpose of this study will refer to the extent to which an individual is perceived as being in a clear, functional state of mind as opposed to being in a confused and clouded state of mind. This decrease in cognitive status is, to some extent, a normal part of the aging process; however, diagnoses of dementia and Alzheimer's represent a decrease in cognitive function beyond what is considered normal aging, these are known as geriatric diseases (Colman, 2008). By creating an eyewitness with an assumed geriatric disease because they are living in a long-term care facility, it will be possible to assess the effect an assumption of decreased cognitive status has on jurors' ratings of eyewitness reliability. 
Level of care was used for two reasons first because the move to a long-term care facility is becoming more common among older adults and second, because the amount of crime happening in long-term care facilities has been increasing. Therefore, knowing how living in a long-term care facility is viewed by mock jurors, with and without a geriatric diagnosis, is important as more adults living in long-term care facilities are facing an increased risk testifying in court. This adds a yet to be explored area to the literature with only one study addressing this in any way, where the location of the crime varied between a nursing home and a private residence (Hodell et al., 2009).

\section{Overview of Juror Research}

The present study will look at juror decision-making from a content perspective, meaning that it will assess how different case factors will effect juror decision-making (Nuñez, McCrea, \& Culhane, 2011). Case factors can include defendant factors like age or gender, witness factors, juror factors, or case factors like DNA (Deoxyribose nucleic acid) evidence or expert testimony (Nuñez et al., 2011). The story model of juror decision making is based on the idea that jurors interpret and intertwine the evidence in order to render a verdict (Pennington \& Hastie, 1986; Pennington \& Hastie, 1991). The story model proposes that jurors take each piece of evidence and assemble them using causal inference to create a story, encompassing aspects of both the Crown and the Defence's story. Jurors then match this story with the most appropriate outcome when rendering a verdict (Pennington \& Hastie, 1991). In this study, the participants will be receiving $100 \%$ of their story from witnesses, as no physical evidence is presented. The extent to which jurors are able to combine the evidence given into a single story is believed to be a strong determinate of their verdicts (Pennington \& Hastie, 1990). Another factor, which 
was found to effect verdicts, when applying the story model to mock jurors was completeness, where an incomplete story resulted in more not guilty verdicts (Pennington \& Hastie, 1992). One of the pillars of a story's coherence is the consistency (Pennington $\&$ Hastie, 1992). Therefore, in this study having two witnesses provide similar accounts of the events would make mock jurors more likely to hold that the information is accurate in their version of the story, while at the same time making this evidence more important to the story. The story model also states that jurors use their world knowledge when interpreting the story and the evidence (Pennington \& Hastie, 1992). In the present study, this may have an effect on the manipulated independent variables and their combinations. For example, a 45 year old who is well living in a long-term care facility will likely be recognised as inconsistent with expectations. Likewise, even when the witness is consistent with expectations, the mock jurors' understanding of dementia, long-term care, and the impact of age on memory will play a role in the story they develop. This is also where some of their stereotypes and past experience will play a role in their interpretation of the older adult eyewitness in the study's testimony and how they will place value on it.

Ecological validity of mock juror studies has been investigated (Nuñez et al., 2011). Ecological validity would be served by mock jury text, including deliberations and trial procedure. There have been concerns as to whether jury decision making can be accurately studied in the lab (see, e.g., Bray \& Kerr, 1979; Diamond, 1997; Nuñez et al., 2011). In order to avoid some of the concerns about external validity and generalizability, this study will use a community sample. Past research has indicated that student mock jurors may be more liberal and less reliant on authority (Wiener, Krauss, \& Lieberman, 2011). Nuñez and colleagues (2011) argue that participant selection should be of minimal 
concern compared to the lack of deliberations.

The Canadian judicial system requires juries to make a group decision. In research on juries, the majority of samples use jurors rather than juries due to practical concerns such as the time, funding, and number of participants it would take to collect a sufficient sample (Nuñez et al., 2011). The two main concerns of the effect of group decision making are conformity, where individuals change their opinion to avoid conflict in a group and polarization, where individuals become more severe in their beliefs based on the persuasive arguments made by others (Nuñez et al., 2011). However, there is evidence that the decisions made by a group may be different than decisions made by an individual. Teger and Pruitt (1967) found that decisions made about risk differ when in a group as opposed to individuals; where larger groups tend to make riskier decisions, with greater reward but lower odds of success. This shift in the individual's decision can be effected by the presentation of persuasive arguments, especially when there is ambiguity in the decision-making (Isenberg, 1986). In replication of earlier European studies Kaplan and Martin (1999), found that in deliberation, lay jurors (undergraduates) were less active in discussion and less influential than trained jurors (law students). These factors, which impact the deliberation process, are what alter the decision made by a juror versus a jury. But how big are these differences? Juries have been found to be more sensitive to biasing information, such as pretrial publicity, than individual jurors (Kerr, Niedermeier, \& Kaplan, 1999). Kerr and colleagues (1999) also found that the weaker the case the more biasing information influenced the outcome, leading to fewer guilty verdicts. Their overall conclusion was that neither jurors nor juries could be labelled as consistently more biased, instead the nature of the case and the individuals make the real 
differences. Every jury is as unique as every juror (Kerr et al., 1999). In a later study, Kerr and colleagues concluded that differences in output from groups to individuals "need not reflect real (qualitative or quantitative) differences" (p. 214) meaning that the ecological validity concerns of working with jurors rather than juries are moot (Kerr, Niedermeier, \& Kaplan, 2000). Some of the down sides of using juries, especially in mock trials, are that individuals may feel less responsibility for the outcome or may find it more difficult to communicate in an effective manner in a group (Nuñez et al., 2011). Although deliberations and the study of juries are important, it remains important to understand how individual jurors react to cases involving the eyewitness testimony of older adults.

\section{The Present Study}

The present study examines eyewitness age 45 years, vs. 65 years, vs. 85 years; geriatric disease, early stage dementia vs. well; and level of care, home vs. long-term care facility on mock jurors' verdicts and a variety of ratings of credibility of the eyewitness (i.e., honesty, senility, reliability, etc.).

\section{Hypotheses}

1. Being older, having dementia, or living in a long-term care facility will elicit more not guilty verdicts and combination two of those will further increase not guilty verdicts leading to interactions.

2. It is hypothesized that a main effect of witness age, level of care, and geriatric disease will be present; where being older, living in a long-term care facility, having dementia will lead to lower verdict confidence and witness character ratings; while leading to higher ratings of eyewitness honesty and senility. 
3. Three two-way interactions between witness age and level of care or dementia are predicted when a greater age is combined with living in a long-term care facility or dementia will decrease verdict confidence and witness character ratings; while increasing ratings of eyewitness honesty and senility, regardless of age when dementia and long-term care facility are combined verdict confidence will decrease.

4. There will also be one three-way interaction, where being older, having dementia, and living in a long-term care facility will lead to lower verdict confidence; however, being younger (45 years) and having dementia or living in a long term care facility is predicted to result in the lowest verdict confidence as this is extremely a-typical for that age group.

5. Scores on the Stereotypes Toward Older People Scale (STOPS) combined with age, dementia, and level of care will predict the witness' ratings on senility. Specifically, high STOPS scores when paired with older ages, dementia, and living in a long-term care facility will result in higher scores on senility.

6. Participants will show primarily negative views on the opinion scales when they have higher scores on the STOPS.

\section{Method}

\section{Participants}

Participants $(N=360)$ were recruited from the community using a Qualtrics panel. Participants received $\$ 1.00$ for participation. All participants were legally eligible to 
participate in a jury trial in Canada, as they were asked whether they were over 18 years of age and able to vote in Canada. Participant age varied from 18 to 82 years, $(M=49.16$, $S D=15.60)$. There were 217 women (61.3\%) and 137 men (38.7\%) surveyed. Participants were asked to identify their ethnicity; 298 (84.2\%) identified themselves as Caucasian, five (1.4\%) African American, 13 (3.7\%) East Asian, nine (2.5\%) South Asian, four (1.1\%) Southeast Asian, six (1.7\%) West Asian, seven (2.0\%) Aboriginal, 10 (2.8) mixed origin, and two $(0.6 \%)$ participants identified themselves as other both of whom specified Canadian origins.

\section{Design}

A 3 (Age of eyewitness; middle aged adult ( 45 years) vs. older adult ( 65 years) vs. elderly adult ( 85 years)) X 2 (Level of care; at home vs. long-term care facility) X 2 (Geriatric disease; none vs. early stage dementia) between-subject factorial design was used. At the beginning of each of the mock trial transcripts, the eyewitness (age manipulation) was asked to state their name, age, and place of residence. Place of residence could be one of two locations; "at home, 572 Rogers lane, Ottawa" or a longterm care facility where they say "South Creek Long-Term Care Facility, 572 Rogers lane, Ottawa" there by giving the level of care variable. Geriatric disease was manipulated when the witness was asked "How is your mental state?" and the witness responds with either "I'm doing well for my age." or "Not so good, I have early stage dementia."

\section{Materials}

The mock trial transcripts consisted of a summary of a trial in which a robbery occurred. The charge of armed robbery was applied to the defendant, thus making a jury 
trial possible under Canadian law. The portion of the trial provided to the mock juror dealt exclusively with the eyewitness testimony concerning the robbery. The trial transcript (see Appendix C: Trial Transcript) included the witnesses first being questioned by the prosecution, followed by a cross-examination by the defense attorney. The witness described how she was drinking her latte when a man with a gun entered the coffee shop. The armed man forced the barista to hand over the cash from the till which he then stuffed into a backpack and then ran out of the store.

Witness age, geriatric disease, and level of care were fully crossed to produce twelve transcript summaries, approximately six pages in length. In addition to witness testimony, bystanders/victims provided testimony that included a description of the offender (i.e., ethnicity, hair descriptors, and age), description of his jacket, time of the robbery, and the bag the criminal put the money in. Testimony on these details was held constant across the transcripts.

After providing their verdicts, mock jurors completed a manipulation check (see Appendix F: Manipulation Check), consisting of five questions to ensure that they were aware of the manipulations in the trial transcript (e.g., "How old was the witness?" and "Where did the witness live?"). When one or more of the questions pertaining to the independent variables were answered incorrectly, the data for that participant was discarded. Participants then completed the eyewitness ratings, followed by STOPS and finally the opinion scale, before reaching the debrief and consent to keep data.

\section{Dependent variables}

Verdict Form (please see Appendix D: Verdict Form). The Verdict form included five items assessing the verdict, strength of confidence, and reason for verdict. 
1) Verdict. Jurors were asked to render a dichotomous verdict of guilty or not guilty for the defendant (i.e., did they believe that the person accused of the murder committed the crime).

2) Confidence in Verdict. On a 6-point Likert scale $(1=$ not at all confident, $6=$ very confident), the mock jurors were asked to rate their level of confidence in the verdict they provided.

Eyewitness Ratings (please see Appendix G: Eyewitness Ratings). The eyewitness ratings measure included eleven items asking mock jurors to think back to the witness Dorothy Collins and consider the effect her testimony had on them. All items are rated on a 6 -point Likert scale $(1=$ not at all adjective, $6=$ very adjective; e.g., $1=$ not at all reliable, $6=$ very reliable) .

1) Witness Credibility. Jurors were asked to rate the overall credibility of the witness.

2) Reliability of Crime Details. Jurors were asked to rate how reliable they perceived the crime details provided by the witness to be, i.e., the jacket, the time of the robbery, and the bag used to transport the money.

3) Witness Believability. Jurors were asked to rate the overall believability of the witness.

4) Reliability of Description of Robber. Jurors were asked to rate how reliable they perceived the description of the robber provided by the witness.

5) Competence. Mock jurors were asked to rate the competence of the witness. 6) Accuracy. Jurors were asked to rate how accurate they found the witness to be. 7) Reliability of Identification. Mock jurors were asked to rate how reliable they 
believed was the lineup identification provided by Mrs. Collins.

8) Confidence. Jurors were asked to rate their overall feeling about the witness' level of confidence during her testimony.

9) Overall reliability. Jurors were asked to rate the overall reliability of the witness.

10) Overall honesty. The jurors were asked to rate the overall honesty of the witness.

11) Senility. The jurors were asked to rate the overall senility of the witness.

Stereotypes Toward Older People Scale (STOPS; please see Appendix I:

Stereotypes Toward Older People Scale (STOPS) was used to measure the extent to which individuals hold both negative and positive stereotypes of older adults. The scale was originally published in 1994 and consists of 14 items (Chumbler, 1994).

Participants were asked to:

"Please read each statement below and indicate the number which best describes to what extent you believe each statement is true of older persons. If you feel the adjective always describes the elderly indicate 7; if you feel the adjective never describes the elderly indicate 1; if you feel somewhere in between indicate any one of the numbers between 1 and 7. If you are neutral or undecided, the midpoint is 4."

This was edited from the original instructions by using the term "indicate" rather than "circle" as the scale was be administered electronically.

The STOPS is divided into four subscales. Intolerance subscale includes four items; an example intolerance item is "Old people get upset easily." The health subscale includes three items, an example of a health item is "old people never fully recover from 
illness." Personality subscale includes four items, an example of a personality item is "Old people are set in their ways." Finally, the activity subscale includes three reverse coded items, such as "old people are physically active."

In the Chumbler (1994) validation study, Cronbach's alpha, that assesses the internal consistency of the items, was 0.82 for the total score and ranged between 0.77 and 0.70 for the subscales. No significant difference was found between the races or genders in the STOPS responses. It was also found to have no significant differences at a two week test-retest interval. The STOPS has content validity since its items are based on items from ten previous scales of stereotypes towards older adults, which were rephrased to allow a consistent scale to be used (Chumbler, 1994).

The STOPS is divided into the four subscales for each scale a higher score indicates greater negative stereotypes of the elderly. For the total score, each subscale score was calculated and then they were all summed together. The current study used only the total score. Items $9,7,8$, and 14 are in the intolerance subscale; items 13,5 , and 12 are in the health subscale; items $1,2,3$, and 4 are in the personality subscale; items 10 , 11 , and 6 are all reverse coded and make up the activity subscale. The author recommends use of the total score (Chumbler, 1994). There were a total of 322 responses to the STOPS scale with a total possible score of 98 scores ranged from 32.00 to 78.00 with a mean of 52.78 and a standard deviation of 7.51 . For these results the Cronbach's alpha, of internal consistency was 0.80 for the intolerance subscale, 0.65 for the health subscale, 0.71 for the personality subscale, and 0.81 for the activity subscale. For the overall STOPS scores the internal consistency was 0.86 . For both the overall and each of the subscales, the alpha would have decreased if any of the items was removed. 
Opinion scale. (Please see Appendix H: Opinion Scales) An opinion scale was included in an attempt to understand what individuals believe it means to have a geriatric disease and to live in a long-term care facility. The opinion scale includes eight items, for example, dichotomous choice questions, for example do you know anyone who lives in a long-term care facility?, select all that apply questions for example which adjectives describe the type of people who live in long-term care facilities? These questions were then re-asked as multiple choice questions, and open-ended question for example what type of care do you believe a long-term care facility provides.

\section{Procedure}

Participants were provided with a link to an online Qualtrics survey. Once they selected the survey from the panel listing, they moved to a screen where they were provided with a digitized consent form (see Appendix A: Informed Consent; which they had the option to print), at the bottom they had the option to click the "I consent to participate" button. The first information the participants was asked to provide was demographics (see Appendix B: Demographic Measure). Then the two opening statements (crown, defense) appeared. Followed by each of the witness statements (direct testimony following by a cross examination), the closing arguments (crown, defense) and finally, judge's instructions. Mock jurors were then be asked to render a verdict; followed by the manipulation check. Finally, participants rated the other dependent variable measures based on the eyewitness (i.e. honesty, senility, etc.). Upon completion, participants viewed a debriefing form (which they had the option to print; see Appendix J: Debriefing Form). Finally, they were presented with a consent to keep data form, that gave them the option to remain participants, then they were thanked for their participation 
(see Appendix K: Consent to Keep Data).

\section{Results}

A total of 1,030 participants were collected using the Qualtrics Panel. Of those recruited, 385 participants declined the informed consent, 180 participants made at least one error in the manipulation check, five participants timed out of the survey, 28 participants stated that they were not legally able to vote in Canada, six participants were under 18 years of age, and 72 participants did not consent to their data being used. The participants who were removed due to errors in the manipulations checks had relatively equal errors between the three manipulations (age, level of care, and geriatric diagnosis) 121,122 , and 121 errors respectively. Of those who made errors 85 participants made one error, 57 made two errors, and 55 made three errors. All participants who failed any manipulation check involving the independent variables were removed from the analyses. A total of 355 participants remained.

\section{Preliminary Analyses}

Examining the participants. Women and men did not render verdicts differently, $\chi^{2}(1)=2.97, p=.10 ;$. Also, there was no significant difference in age between those who rendered guilty verdicts and those who rendered not guilty verdicts, $t(302.574)=0.422, p$ $=.67$. Levene's test was statistically significant, $F(1,352)=11.476, p=.001$, indicating heterogeneity of variance existed between the guilty and not guilty groups; therefore, a corrected df was used. The verdict rendered was found to be independent of ethnicity, where Caucasian participants were compared to other ethnicities $\chi^{2}(1)=0.345, p=.56$.

\section{Assumptions}

Several 3 (age of witness: 45, 65, 85) x 2 (level of care: home, long-term care 
facility) x 2 (dementia: none, early stage) factorial Analysis of Variances (ANOVAs) were run using Statistical Package for the Social Sciences (SPSS) version 20. Data for each of the ANOVAs was screened at the cellular level, using box plots to check for outliers. There was a visual assessment for outliers for each variable, if not mentioned then no outliers were identified in the visual assessment. The assumption of normality can be held because the df error is greater than 20 for all the ANOVAs performed. However, to be safe the data were screened visually at the cellular level for skewness and kurtosis. With a sample as large as this, the standard assessment of z-scores for skewness and kurtosis may be unreliable as $N$ is in the denominator for both formulas and therefore may artificially cause rejection of the assumption of normality (Tabachnick \& Fidell, 2007). Further analyses were done if the z-scores were concerning.

For the ANOVA assessing verdict confidence for the not guilty and guilty analyses homogeneity of variance was screened for using Fmax at the cell level, Fmax is equal to 4.68 and 4.69 , respectively. Which are less than ten and therefore not concerning. Homogeneity of Variance also was screened for at the study level using Levene's, which was non-significant, $F(11,184)=1.596, p=.10$ and $F(11,146)=0.730$, $p=.71$, respectively. The Fmax and Levene's combined indicate that the assumption of Homogeneity of Variance can continue to be held. Normality was assessed based on the skewness value of $z=-3.59, z=-4.18$, respectively, there were some concerns about the skew of the distribution, after a visual inspection; however, it was determined that this skewness was not as severe as originally suspected. Based on the distribution, it would appear that there was a ceiling effect of verdict confidence where the majority of people (52.6\% and $76.6 \%$ of participants, respectively) selected either 5 or 6 indicating that they 
were very confident in their verdict. The kurtosis of verdict confidence was not concerning at $z=0.318, z=0.411$, respectively. Based on these normality concerns a QQ plot was created and the effects of natural log and standardized values assessed. These plots were compared with the untransformed plot, but the improvement did not outweigh the disadvantage of transformation.

Eleven variables were originally used to measure different aspects of participants' perceptions of the eyewitness, Dorothy Collins (credibility, accuracy, competence, believability, senility, honesty, confidence, and reliability [overall, of description, of details, of identification]). Once the data was collected, a composite score was created combining the variables had intercorrelations of Pearson's .70 or greater. This analysis indicated that the majority of the variables (all with the exception of honesty and senility) were highly correlated. There was an exception made of the eyewitness confidence as it was correlated at .70 or greater with all variables except of credibility and reliability of the description of the robber which were correlated at .68 and .69 , respectively. This small deviation among the other consistently high correlations was deemed acceptable.

These correlated, nine variables were then combined into a composite score, which assessed witness character. The new score ranged from 9.00 to $54.00(M=33.36$, $S D=11.64)$. For the ANOVA assessing eyewitness character, homogeneity of variance was screened using Fmax at the cell level, Fmax is equal to 2.23, which is less than ten and therefore not concerning. Homogeneity of Variance also was screened for at the study level using Levene's, which was non-significant, $F(11,322)=0.728, p=.71$. The Fmax and Levene's combined indicate that the assumption of Homogeneity of Variance can continue to be held. Normality was assessed based on the skewness, $z=0.30$ and 
kurtosis, $z=-3.21$. These along with a visual inspection of the data indicated that the normality assumption is held.

As honesty was not correlated with the other witness characteristics it was analysed separately. For the ANOVA assessing the jurors perceived honesty of the eyewitness, homogeneity of variance was screened using Fmax at the cell level, Fmax is equal to 2.06, which is less than ten and therefore not concerning. Homogeneity of Variance was also screened for at the study level using Levene's, which was nonsignificant, $F(11,337)=0.604, p=.82$. The Fmax and Levene's combined indicated that the assumption of Homogeneity of Variance can continue to be held. The assumption of Normality was assessed based on a visual inspection and the skewness, $z=-6.88$ and kurtosis, $z=-0.434$. The skewness value was of concern. It would appear that the majority of participants indicated that they felt the witness was extremely honest $(29.5 \%$ indicated a rating of 5 and $44.1 \%$ indicated a rating of 6 or very honest). A Q-Q plot was created to assess the deviations from normalcy. A Q-Q plot of the original distribution was compared with the natural log transformation and standardization. The Q-Q plot of the original distribution was found to have the least overall deviation from normal; therefore, analyses were run on the original distribution.

Mock jurors' perceptions of senility also were not correlated with the variables combined to create a "witness character" variable; therefore, it was analysed separately. For the ANOVA assessing the jurors perception of the eyewitness' senility, homogeneity of variance was screened using Fmax at the cell level, Fmax is equal to 2.72, which is less than ten and therefore not concerning. Homogeneity of Variance also was screened for at the study level using Levene's, which was non-significant $(F(11,341)=0.657, p=$ 
.78). The Fmax and Levene's combined indicate that the assumption of Homogeneity of Variance can continue to be held. The assumption of normality can be held based on a visual inspection and the skewness, $\mathrm{z}=3.946$ and kurtosis, $\mathrm{z}=-1.235$.

\section{Hypothesis One}

Verdict

Three hundred and fifty-five verdicts were rendered, 158 (44.6\%) participants voted guilty and $196(55.4 \%)$ voted not guilty. A logit log-linear analysis was used to assess whether verdict (guilty/not guilty) was predicted by age, geriatric diagnosis, and level of care. The omnibus test of the model indicated that there was no significant effect of verdict, age, geriatric disease, or level of care (See Table 1 for omnibus results). This indicates that participants' verdicts were not influenced by eyewitness age, geriatric diagnosis, or level of care.

Table 1 Omnibus results of logit analyses of verdict, age, geriatric diagnosis, and level of care.

95\% Confidence

Interval

Standard $\quad$ Lower Upper

\begin{tabular}{ccccccc} 
Source & Estimate & Error & Z-Score & $\mathrm{p}$ & Bound & Bound \\
& & & & & & \\
\hline Verdict & -0.346 & 0.343 & -1.009 & .313 & -1.019 & 0.326
\end{tabular}

$\begin{array}{lllllll}\text { Verdict*Age [45 vs. 85] } & 0.346 & 0.540 & 0.641 & .521 & -0.712 & 1.405\end{array}$

$\begin{array}{lllllll}\text { Verdict*Age [65 vs. 85] } & -0.373 & 0.524 & -0.712 & .477 & -1.399 & 0.654\end{array}$

$\begin{array}{lllllll}\text { Verdict*Geriatric diagnosis } & -0.196 & 0.494 & -0.397 & .692 & -1.165 & 0.773\end{array}$

$\begin{array}{lllllll}\text { Verdict*Level of care } & 0.069 & 0.508 & 0.135 & .893 & -0.928 & 1.065\end{array}$ 
Verdict*Age [45 vs. 85$]^{*}$

$$
\begin{array}{llllll}
0.263 & 0.743 & 0.354 & .724 & -1.193 & 1.718
\end{array}
$$

Geriatric diagnosis

Verdict*Age [65 vs. 85$]^{*}$

$\begin{array}{llllll}0.807 & 0.714 & 1.131 & .258 & -0.592 & 2.206\end{array}$

Geriatric diagnosis

Verdict*Age [45 vs. 85$]^{*}$

$\begin{array}{llllll}-0.236 & 0.738 & -0.320 & .749 & -1.682 & 1.210\end{array}$

Level of Care

Verdict*Age [65 vs. 85$]^{*}$

$\begin{array}{llllll}0.584 & 0.741 & 0.788 & .430 & -0.868 & 2.035\end{array}$

Level of Care

Verdict*Level of care*

Geriatric Diagnosis

$\begin{array}{llllll}0.286 & 0.715 & 0.400 & .689 & -1.115 & 1.687\end{array}$

Verdict*Age [45 vs. 85$]^{*}$

$\begin{array}{lllllll}\text { Level of care* Geriatric } & -0.786 & 1.055 & -0.745 & .456 & -2.853 & 1.281\end{array}$

Diagnosis

Verdict*Age $[65 \text { vs. } 85]^{*}$

$\begin{array}{lllllll}\text { Level of care* Geriatric } & -0.378 & 1.032 & -0.366 & .714 & -2.401 & 1.645\end{array}$

Diagnosis

\section{Hypothesis Two}

Confidence in verdict

In past juror studies verdict confident has been assessed by making the confident into a single variable and multiplying it by the effects coded verdict (-1/+1; e.g., Cohn, Bucolo, Pride, \& Sommers, 2009; Sommers \& Ellsworth, 2001). With the present data, 
however, the resulting distribution is distinctly bimodal, making it inappropriate for use with parametric statistics such as ANOVA. This is also a problem because it drastically increases error variance, which decreases the possible power from the analysis. As such, the decision was made to run two separate ANOVAs. Although the sample size is now quite small, which is a concern for power. The power is actually better served with the small sample size but normal distribution and low error variance than larger sample size but more error variance.

\section{Confidence in verdict: Not Guilty verdicts}

The first 3 X 2 X 2 ANOVA was used to assess the effect of age of witness (45 vs. 65 vs. 85 years), level of care (home vs long-term care facility), and geriatric diagnosis (none vs. early stage dementia) on verdict confidence for mock jurors who rendered not guilty verdict. Geriatric diagnosis was found to have a significant main effect, $F(1,184)=4.48, p=.036$, partial $\omega^{2}=.02$, indicating that approximately $2 \%$ of the variance in verdict confidence for those who rendered a not guilty verdict can be explained by the presence of a geriatric diagnosis plus error (see Table 2 for all means and standard deviations). Participants were more confident when the witness was described as doing well for her age $(M=4.53)$ compared to when she was described as having early stage dementia $(M=4.22)$. None of the other main effects or any of the 2 way interaction were significant.

The above effect may be overshadowed by a significant three-way interaction. The three way interaction was significant, $F(2,184)=3.548, p=.031$, partial $\omega^{2}=.03$, indicating that approximately $3 \%$ of the variance in verdict confidence for those who rendered a not guilty verdict was explained by the interaction of all three variables plus 
error. When holding level of care constant at home, the results indicated that verdict confidence for a witness described as doing well was highest at 45 years $(M=4.53)$, high at 65 years $(M=4.50)$, and low at 85 years $(M=4.06)$. The pattern changed for those identified as living at home when they were described as having early stage dementia. Specifically, the 45 year old was lower than the well 45 year old $(M=4.42)$ but moderate compared to the other age groups. The 65 year old received the lowest verdict confidence $(M=3.80)$. Participants had more confidence in an 85 year old living at home with dementia $(M=4.62)$ than the 85 year old living at home who was well $(M=4.06)$; this difference however, was not statistically significant. When only considering those who were described as living in a long-term care facility, a different pattern emerges. When the eyewitness was described as well, the 45 year old received the highest verdict confidence $(M=5.21)$. The 65 year old $(M=4.32)$ received lower confidence than the well 45 year old and the well 85 year old. The well 85 year old living in the long-term care facility has moderate verdict confidence $(M=4.67)$. When described as having early stage dementia, mock jurors had the least confidence in the 45 year old $(M=3.55)$, the 65 year old the most in the 65 year old with early stage dementia $(M=4.37)$. The 85 year old living in a long-term care facility with early stage dementia elicited only slightly less verdict confidence $(M=4.25)$ from mock jurors who rendered a not guilty verdict compared to the 65 year old with early stage dementia.

There were 12 post-hoc tests done to assess the significant findings above. In order to avoid artificially inflated results, a Bonferrroni correction was applied, making the new alpha level required for statistical significance $.004(.05 / 12=.004)$. Post-hoc analyses of the main effect of geriatric diagnosis are unnecessary as it has only two levels 
and therefore, it is clear that the difference between those two levels is driving the effect making a marginal mean comparison redundant.

For the significant three-way interaction of level of care by geriatric diagnosis by age, the interaction was broken down by simple effects, only one of which was significant. The difference between being well and having dementia for a 45 year old living in a long-term care facility was significant, $F(1,184)=11.44, p<.001$. Where having early stage dementia at 45 in a long-term care facility received significantly lower verdict confidence $(M=3.55)$ than a well 45 year old living in a long-term care facility $(M=5.21)$.

Table 2 Marginal Means (M) and Standard Deviations (SD) for confidence in verdict when a not guilty verdict is rendered.

\begin{tabular}{cccc}
\hline & $N$ & $M$ & $S D$ \\
\hline & Age & & \\
\hline 45 years old & 59 & 4.47 & 1.237 \\
65 years old & 63 & 4.24 & 1.228 \\
85 years old & 74 & 4.41 & 1.281 \\
\hline Well for their Age & Geriatric Diagnosis & & \\
Early Stage Dementia & 96 & 4.53 & 1.214 \\
\hline Living at Home & 100 & 4.22 & 1.268 \\
\hline Long-Term Care Facility & & & \\
\hline
\end{tabular}

Cell Level 


\begin{tabular}{cccc}
\hline 45, well, home & 15 & 4.53 & 1.187 \\
45, well, long-term care & 14 & 5.21 & .802 \\
45, dementia, home & 19 & 4.42 & 1.017 \\
45, dementia, long-term care & 11 & 3.55 & 1.572 \\
65, well, home & 10 & 4.50 & .707 \\
65, well, long-term care & 19 & 4.32 & 1.529 \\
65, dementia, home & 15 & 3.80 & 1.207 \\
65, dementia, long-term care & 19 & 4.37 & 1.116 \\
85, well, home & 17 & 4.06 & 1.298 \\
85, well, long-term care & 21 & 4.67 & 1.155 \\
85, dementia, home & 16 & 4.62 & 1.088 \\
85, dementia, long-term care & 20 & 4.25 & 1.517 \\
& & & \\
\hline
\end{tabular}

\section{Confidence in verdict: Guilty verdicts}

A 3 X 2 X 2 ANOVA was used to assess the effect of age of witness (45 vs. 65 vs. 85 years), level of care (home vs long-term care facility), and geriatric diagnosis (none vs. early stage dementia) on verdict confidence for mock jurors who rendered a guilty verdict. Geriatric diagnosis was found to have a significant main effect, $F(1,146)=$ $6.23, p=.014$, partial $\omega^{2}=.03$, indicating that approximately $3 \%$ of the variance in verdict confidence for those who rendered a guilty verdict can be explained by the presence of a geriatric diagnosis plus error (see Table 2 for all means and standard deviations). Participants were more confident when the witness was described as doing 
well for her age $(M=5.23)$ compared to when she was described as having early stage dementia $(M=4.86)$. The main effect of level of care was also significant, $\mathrm{F}(1,146)=$ $4.33, \mathrm{p}=0.039$, partial $\omega^{2}=.02$, indicating that approximately $2 \%$ of the variance in verdict confidence for those who rendered a guilty verdict can be explained by the living in a long-term care facility plus error. Participants were more confident when the witness lived at home $(M=5.19)$ compared to when the witness lived in a long-term care facility $(M=4.91)$. The main effect of age and none of the interactions were statistically significant. No post hoc test were necessary as both of the significant effects were on variables with two levels and therefore, the significant difference is between those two levels.

Table 3 Marginal Means (M) and Standard Deviations (SD) for confidence in verdict when a guilty verdict is rendered.

\begin{tabular}{cccc}
\hline & $N$ & $M$ & $S D$ \\
\hline & Age & & \\
\hline 45 years old & 50 & 4.88 & .961 \\
65 years old & 56 & 5.16 & .869 \\
85 years old & 52 & 5.10 & .913 \\
\hline Well for their Age & Geriatric Diagnosis & & \\
\hline Early Stage Dementia & 82 & 5.23 & .806 \\
\hline Living at Home & 76 & 4.86 & .873 \\
\hline Long-Term Care Facility & & & \\
\hline
\end{tabular}




\begin{tabular}{cccc}
\hline & Cell Level & & \\
\hline 45, well, home & 8 & 4.75 & 1.035 \\
45, well, long-term care & 15 & 5.47 & .516 \\
45, dementia, home & 16 & 4.81 & .981 \\
45, dementia, long-term care & 11 & 4.27 & 1.009 \\
65, well, home & 16 & 5.44 & .814 \\
65, well, long-term care & 17 & 5.06 & .827 \\
65, dementia, home & 14 & 5.29 & .726 \\
65, dementia, long-term care & 9 & 4.67 & 1.118 \\
85, well, home & 14 & 5.50 & .650 \\
85, well, long-term care & 12 & 4.92 & .900 \\
85, dementia, home & 12 & 5.17 & .937 \\
85, dementia, long-term care & 14 & 4.79 & 1.051 \\
& & & \\
\hline
\end{tabular}

\section{Witness Character}

A 3 X 2 X 2 ANOVA was used to assess the effect of age of witness (45 vs. 65 vs. 85 years), level of care (home, long-term care facility), and geriatric diagnosis (none vs. early stage dementia) on witness character. The main effect of geriatric diagnosis approached significance, $F(1,322)=3.641, p=.057$. Witness character was rated higher when she was well $(M=32.14)$ compared to when she was described as having early stage dementia $(M=34.53)$. None of the other main effects or interactions were significant (see Table 3 for all means and standard deviations). 
Table 4 Marginal Means (M) and Standard Deviations (SD) in eyewitness character.

\begin{tabular}{cccc}
\hline & $N$ & $M$ & $S D$ \\
\hline & Age & & \\
\hline 45 years old & 104 & 32.75 & 11.38 \\
65 years old & 114 & 34.46 & 11.46 \\
85 years old & 116 & 32.83 & 12.05 \\
\hline
\end{tabular}

Geriatric Diagnosis

\begin{tabular}{cccc}
\hline Well for their Age & 171 & 34.53 & 11.76 \\
Early Stage Dementia & 163 & 32.14 & 11.41 \\
\hline & Level of Care & & \\
\hline Living at Home & 163 & 33.63 & 11.32 \\
Long-Term Care Facility & 171 & 33.11 & 11.95 \\
\hline 45, well, home & Cell Level & & \\
45, well, long-term care & 23 & 32.96 & 12.08 \\
45, dementia, home & 29 & 32.86 & 12.97 \\
45, dementia, long-term care & 32 & 33.47 & 11.04 \\
65, well, home & 20 & 31.20 & 9.08 \\
65, well, long-term care & 24 & 37.13 & 11.11 \\
65, dementia, home & 36 & 35.17 & 11.84 \\
65, dementia, long-term care & 29 & 33.00 & 11.11 \\
85, well, home & 25 & 32.60 & 11.73 \\
85, well, long-term care & 28 & 35.25 & 11.11 \\
& 31 & 33.84 & 11.78 \\
\hline & & & \\
\hline & & & \\
\hline
\end{tabular}


85 , dementia, home

85 , dementia, long-term care
27

30
30.30

31.80
11.54

13.57

\section{Honesty}

A 3 X 2 X 2 ANOVA was used to assess the effect of age of witness (45 vs 65 vs. 85), level of care (home vs. long-term care facility), and geriatric diagnosis (none vs. early stage dementia) on perceived honesty of the eyewitness. None of the main effects or interactions for eyewitness honesty were significant or approaching significance (Table 4 for means and standard deviations). As such, no post-hoc analyses were necessary.

Table 5 Marginal Means (M) and Standard Deviations (SD) for honesty.

\begin{tabular}{cccc}
\hline & $N$ & $M$ & $S D$ \\
\hline & Age & & \\
\hline 45 years old & 107 & 4.91 & 1.077 \\
65 years old & 118 & 5.15 & 1.043 \\
85 years old & 124 & 5.09 & 1.028 \\
\hline & Geriatric Diagnosis & & \\
\hline Well for their Age & 175 & 5.06 & 1.029 \\
Early Stage Dementia & 174 & 5.05 & 1.074 \\
\hline & & & \\
\hline Living at Home & 169 & 5.04 & 1.093 \\
Long-Term Care Facility & 180 & 5.07 & 1.012 \\
\hline
\end{tabular}

\section{Cell Level}




\begin{tabular}{cccc}
\hline 45, well, home & 23 & 4.96 & 1.107 \\
45, well, long-term care & 28 & 5.00 & 0.981 \\
45, dementia, home & 35 & 5.00 & 1.085 \\
45, dementia, long-term care & 21 & 4.57 & 1.165 \\
65, well, home & 25 & 5.12 & 1.130 \\
65, well, long-term care & 36 & 5.14 & 1.073 \\
65, dementia, home & 29 & 4.93 & 1.100 \\
65, dementia, long-term care & 28 & 5.43 & 0.836 \\
85, well, home & 30 & 5.10 & 1.029 \\
85, well, long-term care & 33 & 5.03 & 0.951 \\
85, dementia, home & 27 & 5.15 & 1.199 \\
85, dementia, long-term care & 34 & 5.09 & 0.996 \\
& & & \\
\hline
\end{tabular}

\section{Senility}

A 3 X 2 X 2 ANOVA was used to assess the effect of age of witness (45 vs. 65 vs. 85), level of care (home vs, long-term care facility), and geriatric diagnosis (none vs. early stage dementia) on perceived senility of the eyewitness. None of the main effects or interactions for senility were significant (Table 5 for means and standard deviations). However, the interaction between geriatric diagnosis and level of care approached significance, $F(1,341)=2.762, p=.097$. As such, no post-hoc analyses were necessary. 
Table 6 Marginal Means (M), Standard Deviations (SD) for perceived senility of the eyewitness.

\begin{tabular}{cccc}
\hline & $N$ & $M$ & $S D$ \\
\hline & Age & & \\
\hline 45 years old & 109 & 2.74 & 1.287 \\
65 years old & 118 & 2.60 & 1.282 \\
85 years old & 126 & 2.49 & 1.251 \\
\hline
\end{tabular}

\section{Geriatric Diagnosis}

\begin{tabular}{cccc}
\hline Well for their Age & 177 & 2.59 & 1.324 \\
Early Stage Dementia & 176 & 2.62 & 1.222 \\
\hline Living at Home & Level of Care & & \\
\hline Long-Term Care Facility & 171 & 2.55 & 1.266 \\
\hline 45, well, home & 182 & 2.66 & 1.281 \\
\hline 45, well, long-term care & 23 & & \\
45, dementia, home & 29 & 2.57 & 1.308 \\
45, dementia, long-term care & 35 & 2.89 & 1.327 \\
65, well, home & 22 & 2.68 & 1.345 \\
65, well, long-term care & 25 & 2.24 & 1.332 \\
65, dementia, home & 36 & 2.97 & 1.502 \\
65, dementia, long-term care & 29 & 2.48 & 0.911 \\
85, well, home & 28 & 2.57 & 1.200 \\
& 31 & 2.39 & 1.202
\end{tabular}




$\begin{array}{cccc}\text { 85, well, long-term care } & 33 & 2.52 & 1.202 \\ \text { 85, dementia, home } & 28 & 2.64 & 1.446 \\ 85 \text {, dementia, long-term care } & 34 & 2.44 & 1.211\end{array}$

\section{Hypotheses Three}

Stereotypes

A continuous by categorical multiple regression was used to assess whether age (45 vs. 65 vs. 85 years), geriatric diagnosis (aging well vs. early stage dementia), level of care (home vs. long-term care facility), and total score on The Stereotypes Towards Older People Scale (STOPS) could predict participants ratings of senility. The omnibus test was non-significant, $F(4,316)=1.293, p=.27$, indicating that the model as a whole is not an effective predictor of senility (Table 6 for full results). The intercept was significant indicating that the senility rating of a 45 year old, who is well, and living at home is significantly different from zero.

Table 7 Results from a multiple regression assessing whether age, geriatric diagnosis, level of care, and total score on the STOPS predicted mock jurors ratings of eyewitness senility.

\begin{tabular}{cccccccc}
\hline Model & SS & df & MS & $F$ & $p$ & R & $\mathrm{R}^{2}$ \\
\hline Regression & 8.094 & 4 & 2.023 & 1.293 & .273 & .127 & .016 \\
Residual & 494.579 & 316 & 1.565 & & & & \\
Total & 502.673 & 320 & & & & & \\
\hline & & & & & & \\
\hline
\end{tabular}




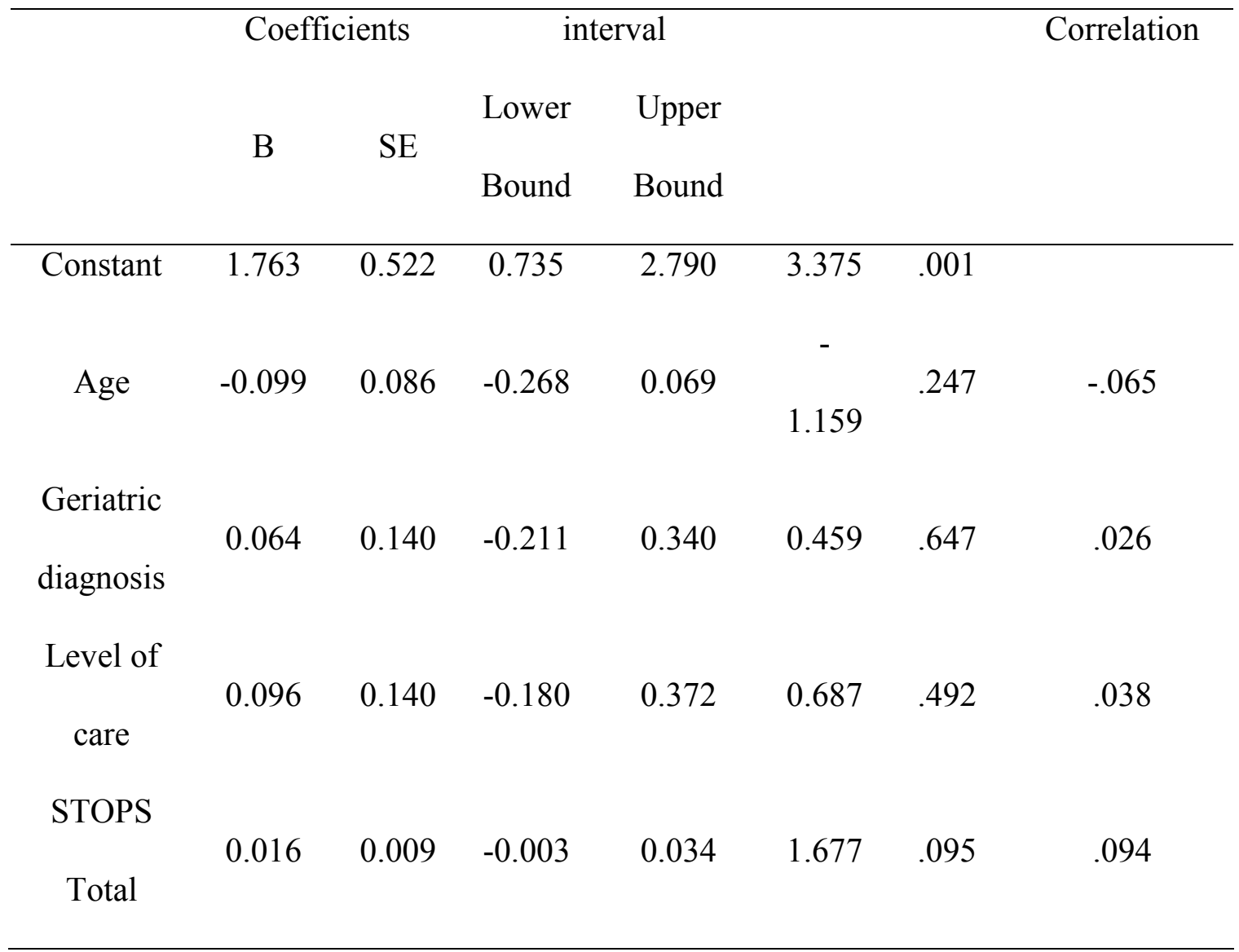

A second continuous by categorical multiple regression was used to assess whether age (45 vs. 65 vs. 85 year), geriatric diagnosis (aging well vs. early stage dementia), level of care (home vs. long-term care facility), and total score on STOPS with the addition of verdict could predict participants ratings of senility. Although, this was not specifically a hypothesized effect, where the verdict rendered had an effect on verdict confidence, one wonders whether verdict would have a similar effect on ratings of senility. Considering that perceiving someone as more senile could give the testimony less value, the addition of verdict as a consideration is important. The omnibus test was significant, $F(5,315)=8.058, p<.001$, indicating that the model as a whole is an effective predictor of senility (Table 7 for full results). The coefficient of determination 
indicates that approximately $11 \%$ of the variance in the mock juror ratings of senility can be explained by this model. Age, geriatric diagnosis, and level of care were not effective predictors of mock jurors' senility ratings. The intercept was significant, $t(319)=4.162, p$ $<.001$, indicating that the average senility rating of a 45 year old, who is well, living at home, has an average STOPS score $(M=52.78 ; S D=7.51)$ and who received a not guilty verdict is 2.988 , which is significantly different from zero. The STOPS total score was marginally significant, $t(319)=-1.933, p=.05$, where for every one unit increase in STOPS total score a 0.017 point increase in senility ratings, indicating that those with higher scores on the STOPS were more likely to give higher ratings of senility. Once the effect of age, geriatric diagnosis, level of care, and verdict have been accounted for the STOPS total score accounted approximately $10 \%$ of the variance in ratings of senility. The effect of verdict was statistically significant, $t(319)=-5.879, p>.001$, meaning that on average every time a guilty verdict was rendered the average senility rating was 0.786 lower compared to when a not guilty verdict was rendered. Once the effects of age, geriatric diagnosis, level of care, and STOPS total score have been accounted for the verdict rendered explains approximately $31 \%$ of the variance in ratings of senility. Table 8 Results from a multiple regression assessing whether age, geriatric diagnosis, level of care, total score on the STOPS, and verdict predicted mock jurors ratings of eyewitness senility.

\begin{tabular}{cccccccc}
\hline Model & SS & df & MS & $F$ & $p$ & $\mathrm{R}$ & $\mathrm{R}^{2}$ \\
\hline Regression & 57.000 & 5 & 11.400 & 8.058 & .000 & .337 & .113 \\
Residual & 445.673 & 315 & 1.415 & & & & \\
Total & 502.673 & 320 & & & & & \\
\hline
\end{tabular}




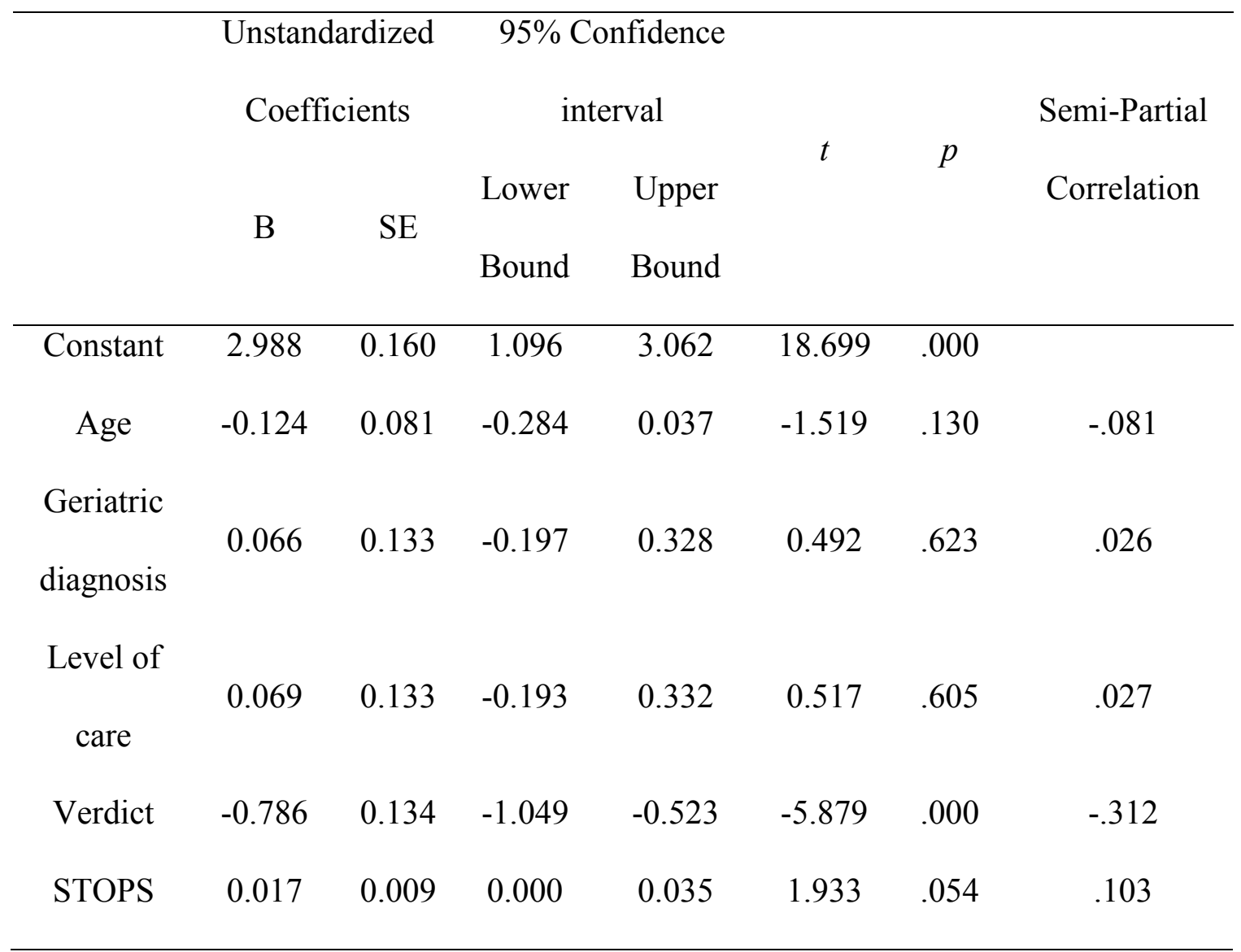

\section{Hypotheses Four}

Exploratory analysis

An exploratory analysis of an individual's opinions and experience with dementia and long-term care facilities was undertaken in an attempt to ascertain public perspective and understanding. Based on the literature assessed, there has been very little research into opinions and perspectives of dementia and long-term care facilities, especially public opinion. Of the participants surveyed, 122 participants $(34.5 \%)$ knew someone who had dementia (although some stated that the person had Alzheimer's), the majority cited a parent or grandparent (55 participants), and the remainder cited a variety of relatives and friends. Participants were reasonably accurate in identifying the typical symptoms of dementia, i.e., forgetting and confusion were by far the most consistently reported (310 
and 309 participants, respectively). The additional symptoms given were aggression, paranoia, anxiety, mood swings, and loss of self. The internal consistency of this measure was extremely low with a Cronbach's alpha of .32. The primary reason for this is that two of the five items were selected by almost all of the participants. This leaving only the variation between the other three items to be considered, all of which were selected less consistently. This is reflected in the fact that Cronbach's alpha would improve on this measure if forgetting and confusion were removed from the scale.

One-hundred and twenty-seven participants (35.9\%) stated they knew someone who lived in a long-term care facility. The majority cited parents, grandparents, and inlaws (56 participants), followed by a friend or acquaintance (38 participants), the remainder compromised extended family. When asked for the number one reason for moving into a long-term care facility, a majority (175 participants, 49.9\%) noted difficulty caring for themselves. Second, third, and forth reasons were: needs nursing care, a geriatric diagnosis, and being old $(63,41$, and 40 participants; $17.9 \%, 11.7 \%$, and $11.4 \%$, respectively). Generally, the positive or neutral reasons for moving to a long-term care facility were selected less often than the negative ones. Also noted was that individuals were either alone or had no family to care for them and that it was for their safety. The question of why move to a long-term care facility had an acceptable Cronbach's alpha of .76 over the 12 items and this could not be improved by the removal of any item.

When asked for the adjectives that best describe someone living in a long-term care facility they chose old as the best adjective (137 participants, 38.8\%). The other primary choices for adjectives were disabled and frail (97 and 67 participants, 27.5\% and 
19.0\%). In general, the positive and neutral adjectives were not endorsed as often as those with negative connotations. When asked which adjectives were not included, participants chose alone, comforted, dependent, ill/sick, needy, and vulnerable. The internal consistency of the adjectives question was .72 , this could only be improved by the removal of the adjective old. This difference however, was incremental (less than .01).

As there were no scales in existence to measure individuals' stereotypes toward those living in long-term care facilities and those with dementia. This measure was reasonable reliable, with an overall internal consistency of .81, for 26 items. Where no items could be removed to improve the Cronbach's alpha. The goal of asking these questions was to assess whether individuals beliefs about what it is to live in a long-term care facility and have a geriatric diagnosis are related to their overall stereotypes of older adults as measured by the STOPS. The results of chi-square test indicated that participants' beliefs about why people move into a long-term care facility are independent from STOPS scores, $\chi^{2}(370)=329.627, p=.94$. However, STOPS scores were highly related to the adjectives participants thought best described the type of people living in long-term care facilities, $\chi^{2}(266)=473.488, p<.001$, indicating that participants with higher STOPS scores were more likely to describe individuals in a longterm care facility as old, senile, or frail compared with those who had lower STOPS scores.

\section{Discussion}

Canada's population is aging. Elder victimization is expected to increase as a greater proportion of our population falls into that category (Carrington, 2001; Shock, 1985; Statistics Canada, 2010). As elder victimization increases, it becomes crucial to 
understand how these older adults will be perceived as they interact with the criminal justice system. When an eyewitness testifies, the reliability of their testimony can weigh heavily on the juror's decision. Individual characteristics of both the juror and the witness can impact the verdict. Though there has been little research on older eyewitnesses, what few studies exist have shown that older adults are seen as less believable than younger witnesses by mock jurors and even police officers (Neal et al., 2012; Wright \& Holiday, 2005). One series of studies found that verdict and confidence in the verdict was altered when the older witness was described as confused or as having a cognitive deficit (Golding et al., 2004; Kinstle et al., 2008). These findings suggest there may be a prejudicial attitude towards older adults that plays out within the judicial context, wherein older witnesses are seen as less reliable in their testimony. With Canada's aging population and the number of people living in nursing homes increasing, understanding whether these factors impact jurors' perceptions and verdict is critical. It is important to know whether an older adult's testimony will be perceived as honest, valid, and reliable. The current study sought to expand the understanding of these factors to better inform the field of psychology, jury research, and the criminal justice system to the potential vulnerabilities and prejudicial attitudes that influence juror decision making when older adults are involved.

There was no direct effect found on verdict, interestingly this was also true of the study by Kinstle et al. (2008) where there was an effect on verdict confidence but not directly on verdict. The absence of significant effect in the current study may be potentially due to participants rendering their verdicts based more on the missing evidence (i.e., hard evidence: DNA, fingerprints, hair, skin, etc.) than the evidence they 
were provided with (i.e. soft evidence: witness testimony). Therefore, when the eyewitness had a geriatric diagnosis jurors felt less confident in their verdict. Confidence may be influential given that verdicts are rendered within a group context in real-life. Within group deliberation, a member of the jury who is less confident in their original verdict might have more difficulty defending it against their peers and may be more persuaded to change their verdict than a juror who is more confident.

The findings of the present study also align with the Kinstle et al. (2008) where researchers described the victim as healthy, confused, or frail and only saw the effect of decreased verdict confidence when the victim was described as confused. It would seem that participants who rendered not guilty verdicts are most concerned when the witness had a cognitive deficit but that other things such as level of care and frailty, which might infer a cognitive deficit, are not sufficient to influence their level of confidence. This may be because those who rendered a not guilty verdict were less confident in their verdict when the witness has early stage dementia. The difference between those with dementia and without is seen most strongly in the 45 year old who lives in a long-term care facility vignettes. Verdict confidence may be lower in this case because mock jurors wanted to believe the witness but found that the evidence was insufficient to render a guilty verdict. Specifically, it is likely that although the mock jurors had warm feelings towards the eyewitness, evidence that was potentially hampered by the cognitive decrease consistent with dementia could not be considered fully trustworthy information to the participants. Therefore, it would be reasonable to infer that the decrease in verdict confidence is based on the want to convict but because they are unsure of the quality of evidence provided by a witness with dementia, they render a not guilty verdict. In other words, when the story 
coherence was detracted by the added issues of cognitive deficit on the part of the eyewitness, the mock juror rejected the story provided by the Crown prosecution. The coherence of the story was further impacted by the age of the 45 year old witness in longterm care and having early stage dementia.

The age of 45 had been of specific interest from the beginning, this was primarily due to the fact that the 45 year old deviated from the stereotype of their age most when living in a long-term care facility and having dementia. It is worth pointing out that the verdict confidence, when rendering a not guilty verdict for a well 45 year old in longterm care, was much higher than one would have anticipated. It is possible that participants made an assumption about the reason this individual was in a long-term care facility, but still "doing well for their age." Regardless of the mock jurors' reasoning, the deviation from expected stereotypes of age for living in a long-term care facility and having dementia caused participants to inflate their confidence when they rendered a not guilty verdict. This infers that they found this group to be specifically poor witnesses. This deviation from the expected norm would reduce story coherence, thus impacting the likelihood of rendering a guilty verdict. In other words, the participants' level of belief and trust in the story narrative provided by the Crown's prosecution and eyewitnesses would decrease. This suggests that jurors' perceptions of confidence of older witnesses may be related to how much the eyewitness conforms to preconceived stereotypes held by jurors. This pattern was somewhat different for jurors who rendered guilty verdicts. When a participant rendered a guilty verdict, they had lower confidence if the witness had dementia or if the witness lived in a long-term care facility. Verdict confidence was likely lower in these cases because although the participants felt that the 
evidence crossed the threshold of reasonable doubt, mock jurors had less trust in the story, but not enough to reject the story. This finding infers that mock jurors had less confidence in the evidence provided by someone with actual or implied cognitive deficit compared to an individual who was well or could care for himself or herself at home.

Unlike the majority of previous research with older adult mock juror studies, the present study found that eyewitness age had no effect on jurors' perceptions of honesty (Allison et al., 2006; Brimacombe et al., 1997). It is possible that there was insufficient power to truly test this hypothesis since, the acquired power .422 for the effect of age on honesty (the greatest effect on honesty). If this study was to be replicated, it would take an approximant sample size of $N=823$ to test for an effect of age on honesty with a power of .80 . Honesty ratings were quite high. This is possibly because there were several corroborating accounts of the robbery, which were sufficiently similar to have participants perceive honesty as high due to the consistency and coherence of the witness' story. This fits with the theoretic framework provided by the Story Model, which considers story coherence to be an important aspect of juror's acceptance of a story (Pennington \& Hastie, 1991). It is possible that coherence positively influences honesty as it seems to have done in this case.

There was also no effect of the manipulations on senility, a new variable first tested in this study. This was surprising as both age, level of care, and geriatric diagnosis would normally be seen as having an effect on senility because as a construct, senility often increases with age. This is exacerbated by geriatric diagnoses and often a symptom associated with someone living in a long-term care facility. As it is suggested by the research that those individuals in a long-term care facility are not able to complete the 
activities of daily living (Feyereisen, Gendron, \& Seron, 1999). As this variable had never been used before, there is little previous evidence about what to expect from a rating of senility or why it did not show an effect in the current study. A definition for senility was provided to participants but perhaps they defined it differently for themselves. Alternatively, participants may have looked to the transcript for evidence of senility, in other words forgetting of information, stumbling during the story, uncertainty about the details, and as none of these were present they felt there was no senility. Perhaps this is encouraging in that jurors may attend more to tone and mannerisms than solely to information presented by the lawyers, which is often manipulated in order to elicit emotions or service a particular outcome. However, it is possible that mock jurors had varying concepts of what senility meant, which may have influenced the ability to detect a significant effect for the manipulation.

When considering the effects of stereotypes, the STOPS scores were a significant predictor of senility ratings (i.e., where having higher STOPS scores increases the senility score). Those who had more negative stereotypes towards older adults were more likely to describe them as senile. The effect of verdict on senility also aligned with this idea, whereby those who rendered a guilty verdict; presumably believing Mrs. Collins, the older witness, overall rated her as less senile than those who rendered a not guilty verdict. These findings may suggest that perceptions of senility and negative stereotypes of older adults are intertwined and may influence verdict outcomes when older eyewitnesses are involved in court cases. This suggests that negative stereotypes against older adults are potentially important considerations in the courtroom. 
As no measure exists for bias towards those with geriatric diagnoses or those living in a long-term care facility, an exploratory measure was created and analysed. The question assessing individuals' beliefs about why people move to a long-term care facility was highly related to scores on the STOPS, indicating that bias against older adults at least partially explains prejudicial attitudes towards those living in long-term care facilities. One item that was particularly informative in understanding perceptions of those living in long-term care facilities is that the most common adjective added to the list describing them was alone/lonely and the most common other reason given for moving to a facility was that they were alone or had no family to care for them. This result aligns with Fiske et al.'s (2002) Stereotype Content Model, where older adults are seen as less competent and the primary emotion towards them is pity. In other words, when an adult lives in a long-term care facility, it increases the potential of triggering negative stereotypes against older adults that are held by jurors. This in turn may influence jury decision-making when an older witness takes the stand and therefore living in a long-term care facility is an important characteristic to consider in such cases.

\section{Limitations}

The type of information presented in the transcript limited this study. The case was intentionally based on eyewitness testimony; however, many of the jurors who voted not guilty felt that there was simply no physical evidence, leaving room for reasonable doubt. This is a challenge to rectify because if strong physical evidence was given, it may outweigh the eyewitness testimony. It would be interesting to do a larger scale study, which would direct participants to make their decision based on the testimony, focusing only on the evidence presented in court and not consider the possible existence of other 
evidence. This would allow determination of how different the verdict split would be, based exclusively on the eyewitness testimony and that it was not based on concern regarding the existence, or lack thereof, of any physical evidence.

This study was limited by the narrow scope of the independent variables. Only dementia was looked at as a geriatric diagnosis; therefore, some of the results could have been based on biases related directly to that disorder and not geriatric diagnoses in general. The same may be true for level of care. There are many levels of care; therefore, an individual's knowledge and ability to differentiate between them would have a notable effect on the results. Adding the other levels of care, such as home care, retirement home, and nursing homes, would allow for a broader assessment of this variable.

This study was limited by the sample size collected. Some of the effects that were nearing significance required a larger sample size in order to assess whether there was a true effect. It was also likely a limitation to have so many dependent variables. Participants may have perceived them as highly overlapping resulting in limited variability both within and across the dependent variables, which could have masked true effects. Nine of variables were highly over lapping with Pearson's intercorrelations ranging from .894 to .681 . Having fewer or more clearly differentiated variables may have bolster the results of this study.

Most of the dependent variables were negatively skewed indicating that there was a ceiling effect, where all those with confidence in the higher range were forced to be grouped together as the scale was small. Using a 10-point Likert scale or a numberless 100-point sliding scale (i.e. a scale that shows two end points but no numbers which participants can slide between the two endpoints to identify their feelings) might decrease 
any bias created by numbers. The use of these scales might increase variance, which would allow better analyses of the manipulations.

There are methodological limitations of this study, which could influence the ecological validity, including the use of online data collection, the lack of deliberations, and trial procedure (Nuñez et al., 2011). There have been concerns as to whether jury decision making can be accurately studied in the lab (see, e.g., Bray \& Kerr, 1979; Diamond, 1997; Nuñez et al., 2011). This concern includes that a brief trial transcript has much less information in it than a trial normally would include; the information in the transcript is also taken in much faster than it would be in a court; and the use of online participants. The decreased amount of information has been tested by comparing videotaped mock trial to transcripts of a mock trial, one study found no effect of method (Pezdek, Avila-Mora, \& Sperry, 2010). Asking participants to devote as much time to a study as they would in a court case is impractical and not feasible; however, it is a consideration. The use of online participants is also a consideration. Some studies have found that it does not influence outcomes (Bornstein \& McCabe, 2005). On the other hand, it is possible that mock jurors' take their job less seriously, which could be influenced by the lack of time committed to the decision making.

A more concerning limitation is the lack deliberation, which may have an important influence on the final verdict rendered. Some previous research has found that deliberation may eliminate some bias, caused by evidence, which was deemed inadmissible (London \& Nunez, 2000). However, other studies have found no increase in legal understanding and that deliberation rarely changed the majority individual verdict (Kerr et al., 1999; Kerr et al., 2000; Wiener et al., 2004). 


\section{Future Research}

Future studies addressing older witnesses should examine different age ranges to see if an effect of age can be more consistently found, perhaps using 25 or 30 year age differences. It might also be advisable to make the age a 4-level manipulation to compare younger adults to older adults rather than just middle-aged adults to older adults.

Future studies should consider more specific geriatric diagnoses given mock jurors in this study seemed to be swayed by it, such that their verdict confidence decreased when a geriatric diagnosis was present. This could include the addition of other geriatric diagnoses such as Alzheimer's Disease, Parkinson's Disease, and Huntington's Disease. All of which have a unique sets of symptoms, yet all impact the cognitive status of an older adult, as well as their ability to complete the activities of daily living. Also, it would be interesting to investigate the way mock jurors interpret individuals with diseases, which do not impact their cognitive abilities but limit their physical abilities.

Level of care has, by far, the least research done on it. The most appropriate first step would be to do a broad assessment to test the knowledge of those in the public about the purpose of long-term care facilities, likely by creating a measure of stereotypes about the individuals living in the facilities. It would be informative to compare the stereotypes of those living in a nursing home or receiving home care. Location of crime also may be interesting to examine. For example, if a crime occurred in a long-term care facility versus the home of the person testifying. Future research should also focus in on the interaction of geriatric diagnosis and level of care to assess whether it is a compounding effect, where having either decreases reliability but having both severely decreases the 
reliability. This will increase understanding of how negative stereotypes of older adult eyewitnesses influence verdicts.

As legislation in changing in regard to special measures to support the testimony of vulnerable persons, including older adults, especially those with geriatric diagnoses, it would be prudent to assess how mock jurors will respond to these special measures (Bala et al., 2011; Hall, 2007). Future studies should manipulate no application for special measures, successful applications, and unsuccessful applications. These manipulations would allow better understanding of how measures, meant to support vulnerable individuals in the courtroom, are interpreted by jurors and whether they have an effect on verdicts.

This study would also be useful to replicate with jurors of different age groups as research has shown that stereotypes of older adults is notably different among different age groups (Hummert et al., 1994; Hummert et al., 1995). This would include both young (over 18) and older adults as jurors, as some research indicates that it is the elderly who hold the greatest bias against older adults (Davis \& Friedrich, 2010) suggesting a possible inverse age saliency in jury decision making (i.e., that people of a similar age hold more negative views of people of the same age). It also would be interesting to measure individuals' relationships with their grandparents as some stereotyping theory indicates that this is the basis for their stereotypes towards older adults (Edwards, 1984; Pecchioni \& Croghan, 2002). This type of research would also help expand existing knowledge of older adult eyewitnesses, identifying stereotypes, potential moderators, and jurors' perceptions and decision-making. 
Further research on a measure of bias towards those living in long-term care facilities and those with geriatric diagnoses should also be pursued. The validation of this type of measure would be extremely useful in furthering the mock juror research on older adults.

\section{Implications}

The results of this study indicate that mock jurors do consider when a witness is described as having early stage dementia or living in a long-term care facility. In this case, the diagnosis does not seem to have had a direct effect on verdict; however, it would seem that geriatric diagnosis and level of care could play a role in juror's confidence level in the eyewitness. In a scenario where the jurors were required to deliberate, this might increase their likelihood to be swayed in their verdict. For older adults there must be a fine balance between receiving a fair day in court and not over estimating the value of a testimony that is flawed by fractures of the mind and errors. The results of this study indicated that jurors were primarily unconcerned with age of the eyewitness. Some negative stereotypes against older adults do exist and may come into play in the courtroom. 


\section{References}

Allison, M., Brimacombe, C. A. E., Hunter, M. A., \& Kadlec, H. (2006). Young and older adult eyewitnesses' use of narrative features in testimony. Discourse Processes, 41(3), 289-314.

Alzheimer's Society of Canada (2010). Rising Tide: The Impact of Dementia in Canada. Available at: http://www.alzheimer.ca/english/rising_tide/rising_tide.htm.

American Psychiatric Association. (2013). Diagnostic and statistical manual of mental disorders (5th ed.). Arlington, VA: American Psychiatric Publishing.

Astrom, S., Bucht, G., Eisemann, M., Norberg, A., \& Saveman, B.I. (2002). Incidence of violence towards staff caring for the elderly. Scandinavian Journal of Caring Sciences, 16(1), 66-72.

Bachman, R., Dillaway, H., \& Lachs, M. S. (1998). Violence against the elderly: A comparative analysis of robbery and assault across age and gender groups. Research on Aging, 20(2), 183-198.

Bala, N., Paetsch, J. J., Bertrand, L. D., Thomas, M. (2011). Testimonial support provisions for children and vulnerable adults (Bill C-2): Case law review and perceptions of the judiciary. (Catalogue number J2-367/2011F). Ottawa, On: Canadian Research Institute for Law and the Family. http://www.justice.gc.ca/eng/rp-pr/fl-1f/famil/rr10_vic3/rr10_vic3.pdf (accessed August $\left.13^{\text {th }}, 2015\right)$.

Barnes, L. L., Mendes de Leon, C. F., Lewis, T. T., Bienias, J. L., Wilson, R. S., \& Evans, D. A. (2008). Perceived discrimination and morality in a population-based study of older adults. American Journal of Public Health, 98(7), 1241-1247. 
Barrett, A. E., \& Cantwell, L. E. (2007). Drawing on stereotypes: Using undergraduates' sketches of elders as a teaching tool. Educational Gerontology, 33, 327-348.

Bornstein, B. H., \& McCabe, S. G. (2005). Jurors of the absurd? The role of consequentiality in jury simulation research. Florida State University Law Review, 32, 443-467.

Boyce, J. (2013). Adult Criminal Court Statistics in Canada, 2011/2012. (Catalogue number 85-002-X). Ottawa, Ont: Statistics Canada. http://www.statcan.gc.ca/daily-quotidien/130613/dq130613c-eng.htm (accessed June $\left.6^{\text {th }}, 2014\right)$.

Bray, R. M., \& Kerr, N. L. (1979). Use of the simulation method in the study of jury behavior: Some methodological considerations. Law and Human Behavior, 3(1/2), 107-119.

Brimacombe, C. A. E., Jung, S., Garrioch, L., \& Allison, M. (2003). Perceptions of older eyewitnesses: Will you believe me when I'm 64? Law and Human Behavior, 27, 507-522.

Brimacombe, C. A. E., Quinton, N., Nance, N., \& Garrioch, L. (1997). Is age irrelevant? Perceptions of young and old adult eyewitnesses. Law and Human Behavior, 21, 619-634.

Butler, R. N. (1969). Age-ism: Another form of bigotry. The Gerontologist, 9(4), 243246.

Butler, R. N. (1975). Psychiatry and the elderly: An overview. American Journal of Psychiatry, 132, 893-900. 
Carrington, P. J. (2001). Population aging and crime in Canada, 2000-2041. Canadian Journal of Criminology, 44(3), 331-356.

Chumbler, N. R. (1994). The development and reliability of a stereotypes toward older people scale. College Student Journal, 28, 220-229.

Cohn, E. S., Bucolo, D., Pride, M., \& Sommers, S. R. (2009). Reducing White juror bias: The role of race salience and racial attitudes. Journal of Applied Social Psychology, 39, 1953-1973.

Colman, A. M. (Eds.). (2008). A Dictionary of Psychology (3 $3^{\text {rd }}$ ed.). Oxford, UK: Oxford University Press.

Crumb, D. J., \& Jennings, K. (1998, February). Incidents of patient abuse in health care facilities are becoming more and more common place. Dispute Resolution, 37-43.

Davis, N. C., \& Friedrich, D. (2010). Age stereotypes in middle-aged through old-old adults. International Journal of Aging and Human Development, 70(3), 199-212.

Diamond, S. S. (1997). Illuminations and shadows from jury simulations. Law and Human Behavior, 21(5), 561-571.

Dodson, C. S., \& Krueger, L. E. (2006). I misremember it well: Why older adults are unreliable eyewitnesses. Psychonomic Bulletin \& Review, 13(5), 770-775.

Eaton, T. E., Ball, P. J., \& O’Callaghan, M. G. (2001). Child-witness and defendant credibility: Child evidence presentation mode and judicial instructions. Journal of Applied Social Psychology, 31(9), 1845-1858.

Edwards, C. P. (1984). The age group labels and categories of preschool children. Child Development, 55(2), 440-452. 
Feyereisen, P., Gendron, M., \& Seron, X. (1999). Disorders of everyday actions in subjects suffering from senile dementia of Alzheimer's type: An analysis of dressing performance. Neuropsychological Rehabilitation: An International Journal, 9(2), 169-188.

Fiske, S. T., Cuddy, A. J. C., Glick, P., and Xu, J. (2002). A model of (often mixed) stereotype content: Competence and warmth respectively follow from perceived status and competition. Journal of Personality and Social Psychology, 82(6), 878902.

Garcia-Bajos, E., Migueles, M., \& Aizpurua, A. (2012). Bias of script-driven processing in eyewitness memory in young and older adults. Applied Cognitive Psychology, $26,737-745$.

Golding, J. M., Allen, J., Yozwiak, J. A., Marsil, D. F., \& Kinstle, T. S. (2004). Perceptions of elder neglect in the courtroom. Journal of Elder Abuse \& Neglect, $16(1), 23-46$.

Golding, J. M., Yozwiak, J. A., Kinstle, T. L., \& Marsil, D. F. (2005). The effect of gender in the perception of elder physical abuse in court. Law and Human Behavior, 29(5), 605-614.

Hall, M. (2007). The use and abuse of special measures: Giving victims the choice? Journal of Scandinavian Studies in Criminology and Crime Prevention, 8(Suppl 1), 33-53.

Hirschel, J. D., \& Rubin, K. B. (1982). Special problems faced by elderly victims of crime. Journal of Sociology and Social Welfare, 9(2), 357-374. 
Hitzig, S. L., Sheppard, C., Singh Mukhi, J., Mathur, A., Spalter, T., \& McDonald, L. Resident-to-resident elder abuse: A scoping review. Poster presented at the 42 nd Annual Scientific and Educational Meeting of the Canadian Association on Gerontology, Halifax, NS, October 17-21, 2013.

Hodell, E. C., Golding, J. M., Yozwiak, J. A., Bradshaw, G. S., Kinstle, T. L., \& Marsil, D. F. (2009). The perception of elder sexual abuse in the courtroom. Violence Against Women, 15(6), 678-698.

Hummert, M. L. (1990). Multiple stereotypes of elderly and young adults: A comparison of structures and evaluations. Psychology and Aging, 5, 182-193.

Hummert, M. L., Garstka, T. A., Shaner, J. L., \& Strahm, S. (1994). Stereotypes of the elderly held by young, middle-aged and elderly adults. Journal of Gerontology: Psychological Sciences, 49, 240-249.

Hummert, M. L., Garstka, T. A., Shaner, J. L., \& Strahm, S. (1995). Judgements about stereotypes of the elderly: Attitudes, age associations, and typicality ratings of young, middle-aged, and elderly adults. Research on Aging, 17(2), 168-189.

Hummert, M. L., Shaner, J. L., Garstka, T. A., \& Henry, C. (1998). Communication with older adults: The influence of age stereotypes, context, and communicator age. Human Communication and Research, 25(1), 124-151.

Isenberg, D. J. (1986). Group polarization: Acritical review and meta-analysis. Journal of Personality and Social Psychology, 50(6), 1141-1151.

Kaplan, M. F., \& Martin, A. M. (1999). Effects of differential status of group members on process and outcome of deliberation. Group Process \& Intergroup Research, 2(4), 347-364. 
Kerr, N. L., Niedermeier, K. E., \& Kaplan, M. F. (1999). Bias in jurors vs bias in juries: New evidence from the SDS perspective. Organizational Behavior and Human Decision Processes, 80(1), 70-86.

Kerr, N. L., Niedermeier, K. E., \& Kaplan, M. F. (2000). On the virtues of assuming minimal differences in information processing in individuals and groups. Group Processes \& Intergroup Relations, 3(2), 203-217.

Kinstle, T. S., Hodell, E. C., \& Golding, J. M. (2008). The impact of juror characteristics and victim health status on perception of elder physical abuse. Journal of Interpersonal Violence, 23(9), 1143-1161.

Kwong See, S. T., \& Heller, R. B. (2004). Judging older targets' discourse: How do age stereotypes influence evaluations? Experiments Aging Research, 30, 63-73.

Kwong See, S. T., Hoffman, H. G., \& Wood, T. L. (2001). Perception of an old female eyewitness: Is the older eyewitness believable? Psychology and Aging, 14(2), 346-350.

Lachs, M. S., Bove, C., Wearing, M. H., Williams, C., Bachman, R., \& Cooney, L. M. (2003). The clinical epidemiology of crime victimization in older adults: A multidisciplinary pilot study. Journal of Elder Abuse \& Neglect, 13(3), 79-90.

Lachs, M. S., Bachman, R., Williams, C. S., Kossack, A., Bove, C., \& O’Leary, J. R. (2006). Violent crime victimization increases the risk of nursing home placement in older adults. The Gerontologist, 46(5), 583-589.

Lachs, M., Bachman, R., Williams, C., Kossack, A., Bove, C., \& O’Leary, J. (2004). Older adults as crime victims, perpetrators, witnesses and complainants: A 
population-based study of police interactions. Journal of Elder Abuse \& Neglect, 16(4), 25-40.

Lapuk, D. S. (2007). Resident aggression in a long-term care setting: Concerns and meanings from perspectives of other residents. (Unpublished doctoral dissertation). The University of Manitoba, Manitoba, Canada.

List, J. A. (1986). Age and schematic differences in the reliability of eyewitness testimony. Developmental Psychology, 22(1), 50-57.

London, K., \& Nunez, N. (2000). The effect of jury deliberations on jurors' propensity to disregard inadmissible evidence. Journal of Applied Psychology, 85(6), 932-939.

Lomax-Cook, F. (2001). Age stereotype. In G. L. Maddox (Ed.), The Encyclopedia of Aging: Vol. A-L. (3rd ed., pp. 45-46). New York: Springer.

Macie, D. M., Hamilton, D. L., Russkind, J., \& Rosselli, F. (1996). Social psychological foundations of stereotype formation. In C. N. Macrae, C. Stangor, \& M. Hewstone (Eds.), Stereotypes and stereotyping (pp. 41-78). New York \& London: Guilford.

Macnicol, J. (2006). Age discrimination: An historical and contemporary analysis. Cambridge, United Kingdom: Cambridge University Press.

McDonald, L., Sheppard, C., Hitzig, S. L., Spalter, T., Mathur, A., \& Singh Mukhi, J. (2015). Resident-to-resident abuse: A scoping review. The Canadian Journal of Aging, 34(2), 215-236.

Mello, E. W., \& Fisher, R. P. (1996). Enhancing older adult eyewitness memory with the cognitive interview. Applied Cognitive Psychology, 10, 403-417. 
Mercer, S. O., Heacock, P., \& Beck, C. (1993). Nurse's aids in nursing homes:

Perceptions of training, work loads, racism, and abuse issues. Journal of Gerontological Social Work, 21, 95-112.

Mitchell, K. J., Johnson, M. K., \& Mather, M. (2003). Source monitoring and suggestibility to misinformation: Adult age-related differences. Applied Cognitive Psychology, 17, 107-119.

Moriya, S., Tei, K., Miura, H., Inoue, N., \& Yokoyama, T. (2013). Associations between higher-level competence and general intelligence in community-dwelling older adults. Aging \& Mental Health, 17(2), 242-249.

Neal, T. M. S., Christiansen, A., Bornstein, B. H., \& Robicheaux, T. R. (2012). The effects of mock jurors' beliefs about eyewitness performance on trial judgements. Psychology, Crime \& Law, 18(1), 49-64.

Nunez, N., McCoy, M. L., Clark, H. L., \& Shaw, L. A. (1999). The testimony of elderly victim/witnesses and their impact on juror decisions: The importance of examining multiple stereotypes. Law and Human Behavior, 23(4), 413-423.

Nuñez, N., McCrea, S. M., \& Culhane, S. E. (2011). Jury decision making research: Are researchers focusing on the mouse and not the elephant in the room? Behavioral Science and the Law, 29, 439-451.

Ogrodnik, L. (2007). Seniors as Victims of Crime: 2004 and 2005. (Catalogue number 85F0033MIE - No. 014). Ottawa, Ont: Statistics Canada. http://www.statcan.gc.ca/pub/85f0033m/85f0033m2007014-eng.htm (accessed August $\left.7^{\text {th }}, 2014\right)$. 
Palmore, E. (2001). The ageism survey: First findings. The Gerontologist, 41(5), 572575.

Pecchioni, L. L., \& Croghan, J. M. (2002). Young adults' stereotypes of older adults with their grandparents as targets. Journal of Communication, 54(4), 715-730.

Pennington, N., \& Hastie, R. (1986). Evidence evaluation in complex decision making. Journal of Personality and Social Psychology, 51(2), 242-258.

Pennington, N., \& Hastie, R. (1990). Practical implications of psychological research on juror and jury decision making. Personality and Social Psychology Bulletin, 16(1), 90-105.

Pennington, N., \& Hastie, R. (1991). A cognitive theory of juror decision making: The story model. Cardozo Law Review, 13(2-3), 519-557.

Pennington, N., \& Hastie, R. (1992). Explaining the evidence: Tests of the story model for juror decision making. Journal of Personality and Social Psychology, 62(2), 189-206.

Pezdek, K., Avila-Mora, E., \& Sperry, K. (2010). Does trial presentation medium matter in jury simulation research? Evaluating the effectiveness of eyewitness expert testimony. Applied Cognitive Psychology, 24(5), 673-690.

Podgorski, C. A., Tariot, P. N., Blazina, L., Cox, C., \& Leibovici, A. (1996). Crossdiscipline disparities in perceptions of mental disorders in a long-term care facility. Journal of the American Geriatrics Society, 44(7), 792-797.

Quinn, M. J., \& Tomita, S. K. (1997). Elder abuse and neglect: Causes, diagnosis, and intervention strategies ( $2^{\text {nd }}$ ed.). New York, NY: Springer.

R. v. Khelawon, [2006] 2 S.C.R. 787, 2006 SCC 57 
Robinson, T., Gustafson, B., \& Popovich, M. (2008). Perceptions of negative stereotypes of older people in magazine advertisements: Comparing the perceptions of older adults and college students. Ageing \& Society, 28, 233-251.

Rodriguez v. State, 772 S.W.2d 167 (Tex. Ct. App. 14 Dist. 1989)

Searcy, J., Bartlett, J. C., \& Memon, A. (2000). Influence of post-event narratives, line-up conditions and individual differences on false identification by young and older witnesses. Legal and Criminological Psychology, 5, 219-235.

Shinoda-Tagawa, T., Leonard, R., Pontikas, J., McDonough, J. E., Allen, D., \& Dreyer, P. I. (2004). Resident-to-resident violent incidents in nursing homes. Journal of American Medical Association, 291(5), 591-598.

Shock, N.W. (1985) Longitudinal Studies of Aging in Humans. In Finch, C.E., Schneider, E.L. (Eds.), Handbook of the Biology of Aging (721-743). New York: Van Nostrand Reinhold.

Sommers, S. R., \& Ellsworth, P. C. (2001). White juror bias: An investigation of prejudice against Black defendants in the American courtroom. Psychology, Public Policy, and Law, 7, 201-229.

Statistics Canada. (2007). 2006 Census Dictionary. Statistics Canada Catalogue no. 92566-XWE. Ottawa, On: Statistics Canada. http://www12.statcan.ca/english/census06/reference/dictionary/index.cfm (accessed June $6^{\text {th }}$, 2014).

Statistics Canada. (2010). Population Projections for Canada, Provinces and Territories: 2009 to 2036. (Catalogue number 91-520-X). Ottawa, On: Statistics Canada. 
http://www23.statcan.gc.ca/imdb/p2SV.pl?Function=getSurvey\&SDDS=3602\&la $\underline{\mathrm{ng}}=\mathrm{en} \& \mathrm{db}=\mathrm{imdb} \& \mathrm{adm}=8 \& \mathrm{dis}=2\left(\right.$ accessed December $\left.1^{\text {st }}, 2013\right)$.

Statistics Canada. (2012). Living Arrangments of Seniors: Families, housholds and marital status structural type of dwelling and collectives, 2011 census of population. (Catalogue number 98-312-X2011003). Ottawa, On: Statistics Canada. http://www12.statcan.gc.ca/census-recensement/2011/as-sa/98-312-x/98312-x2011003 4-eng.cfm (accessed November 15 $\left.5^{\text {th }}, 2013\right)$.

Sweller, J., \& Cooper, G. A. (1985). The use of worked examples as a substitute for problem solving in learning algebra. Cognition and Instruction, 2(1), 59-89.

Tabachnick, B. G., \& Fidell, L. S. (2007). Experimental designs using ANOVA. Thomson Brooks Cole: Belmont, CA.

Teger, A. I., \& Pruitt, D. G. (1967). Components of group risk taking. Journal of Experimental Social Psychology, 3(2), 189-205.

Umphrey, D., \& Robinson, T. (2007). Negative stereotypes underlying other-person perceptions of the elderly. Educational Gerontology, 33, 309-326.

Wiener, R. L., Krauss, D. A., \& Lieberman, J. D. (2011). Mock jury research: Where do we go from here? Behavioral Sciences and the Law, 29, 467-479.

Wiener, R. L., Rogers, M., Winter, R., Hurt, L., Hackney, A., Kadela, K., ... Morasco, B. (2004). Guided jury discretion in capital murder cases: The role of declarative and procedural knowledge. Psychology, Public Policy, and Law, 10(4), 516-576.

Wilcock, R., \& Bull, R. (2010). Novel lineup methods for improving the performance of older eyewitnesses. Applied Cognitive Psychology, 24, 718-736. 
Wilcock, R. A., Bull, R., \& Vrij, A. (2005). Aiding the performance of older eyewitnesses: Enhanced non-biased line-up instructions and line-up presentation. Psychiatry, Psychology and Law, 12(1), 129-140.

Wood, F. (2007). Bullying in nursing homes: Prevalence and consequences to psychological health. (Unpublished doctoral dissertation). Walden University, USA.

Wright, A. M., \& Holliday, R. E. (2005). Police offers' perceptions of older eyewitnesses. Legal and Criminal Psychology, 10, 211-223. 


\section{Appendix A: Informed Consent}

\section{Informed Consent Form}

The purpose of informed consent is to ensure that you understand the purpose of the study and the nature of your involvement. Informed consent must provide sufficient information such that you have the opportunity to determine whether or not you wish to participate in the study.

\section{Present study: To Convict or Not To Convict}

Research personnel: The following people will be involved in this research project and may be contacted at any time: Elizabeth Schultheis (Student, Principal Investigator, elizabethschultheis@cmail.carleton.ca, 613-520-2600, ext. 3695) or Dr. Joanna Pozzulo (Faculty Advisor, Joanna.Pozzulo@carleton.ca, 613-520-2600, ext. 1412).

Concerns: If you should have any ethical concerns about this study please contact, Dr. Shelley Brown (Chair, Carleton University Psychology Research Ethics Board, shelley.brown@carleton.ca, 613-520-2600, ext. 1505). Should you have any other concerns please contact, Dr. Adelle Forth (Associate Chair, Department of Psychology, adelle.forth@carleton.ca, 613-520-2600, ext. 1267).

Purpose: The purpose of this study is to examine mock jurors' assessment of trial facts and their subsequent verdict along with several other ratings.

Task requirements: You will be asked to read a transcript of a trial involving an armed robbery. You will be asked to complete some questionnaires requesting your demographic information, thoughts and opinions on the case you read, and to determine a verdict in the case.

Duration and locale: This study will be completed online in one testing session that will last approximately 25 minutes.

Remuneration: Any incentive you will receive for completing this survey will be in the amount of $\$ 1.00 \mathrm{CND}$ and provided to you in accordance with the terms and conditions of your membership in the survey panel through which you have received the invitation to participate.

Potential risk/discomfort: There are no potential physical risks involved in this experiment. There is a slight risk for discomfort when reading about a trial involving an armed robbery. Should you experience any unease, you have the right to withdraw from the study without penalty.

Anonymity/Confidentiality: The data collected in this experiment are strictly confidential. All data are coded such that your name is not associated with the responses you provide. Any identifying information associated with your code will be confined to a single page that will be separated from your questionnaire, and kept in a separate, secured file by the research investigators, who will keep this information confidential. Only members of the Forensic Psychology Research Laboratory will have access to the data. 
We collect data through the software Qualtrics, which uses servers with multiple layers of security to protect the privacy of the data (e.g., encrypted websites and pass-word protected storage). Please note that Qualtrics is hosted by a server located in the USA. The United States Patriot Act permits U.S. law enforcement officials, for the purpose of an anti-terrorism investigation, to seek a court order that allows access to the personal records of any person without that person's knowledge. In view of this we cannot absolutely guarantee the full confidentiality and anonymity of your data. With your consent to participate in this study you acknowledge this. Your name and e-mail will be kept in our participant database so that we can keep track of who has completed our study. Your data will be kept on the Qualtrics database will be kept for five years at that time the Qualtrics data and any subsequent versions will be destroyed. The information in this database cannot be matched to your responses. All the information you provide will be strictly confidential. These data will only be used for research at Carleton University.

Right to withdraw: In addition, you may refrain from answering any questions on the questionnaire if you are uncomfortable or otherwise do not want to. At any point in the study, you may withdraw without penalty in accordance with the terms and conditions of your membership in the survey panel through which you have received the invitation to participate, generally, you will not lose any already accrued, but will revive no compensation for the current study. At the end of the study, you will be asked if you would like to withdraw your data from the study and will have the option of doing so immediately if you should so wish.

This study has received clearance by the Carleton University Psychology Research Ethics Board (15-076).

I have read the above form and understand the conditions of my participation. My participation in this study is voluntary, and I understand that if at any time I wish to leave the experiment, I may do so without having to give an explanation and with no penalty whatsoever. Furthermore, I am also aware that the data gathered in this study are confidential and anonymous with respect to my personal identity. By checking this box, I'm indicating that I agree to participate in this study.

I have read the above form and understand the conditions of my participation. My participation in this study is voluntary, and I understand that if at any time I wish to leave the experiment, I may do so without having to give an explanation and with no penalty whatsoever. Furthermore, I am also aware that the data gathered in this study are confidential and anonymous with respect to my personal identity. By checking this box, I'm indicating that I disagree to participate in this study. 


\section{Appendix B: Demographic Measure}

\section{Demographics}

Your age:

Your gender:

Primary language:

Ethnicity: Please indicate which ethnic group you would consider yourself to belong to (optional):

$\square \quad$ White (e.g., European)

Black (e.g., African, African American, African Canadian, Caribbean)

$\square$ East Asian (e.g., Chinese, Japanese, Korean, Polynesian)

$\square$ South Asian (e.g., Indian, Pakistani, Sri Lankan, Bangladeshi)

$\square$ Southeast Asian (e.g., Burmese, Cambodian, Filipino, Laotian, Malaysian, Thai, Vietnamese)

$\square$ West Asian (e.g., Arabian, Armenian, Iranian, Israeli, Lebanese, Palestinian, Syrian, Turkish)

$\square$ Latin American (e.g., Mexican, Indigenous Central, South American)

$\square$ Aboriginal Canadian/Native Canadian/First Nations

$\square$ Mixed origin, please specify:

$\square$ Other: 


\title{
Appendix C: Trial Transcript
}

\author{
Trial Transcript
}

This is a trial summary from court proceedings where Mr. Mathew Turner, a 32 year old male, is accused of armed robbery of a coffee shop. The sections below consist of the witness' testimony.

Judge: Mathew Turner has been charged under sections 343(d) anyone who steals from any person while armed with an offensive weapon or imitation thereof under the Canadian Criminal Code. The burden of proof, under the law, rests with the Crown. The case they present must prove the defendant guilty beyond a reasonable doubt. As a juror, it is your responsibility to listen to all evidence and weigh the facts. Refrain from allowing any bias, personal or emotional, from swaying your judgments about the facts of the case. The first statements you will hear are the opening statements from the lawyers of the Crown and Defence. Remember these are not evidence, simply a statement summarizing their main arguments. The lawyers will then each present witnesses, whom they will question. Each witness will then be cross-examined by the opposing counsel. Afterwards, you will hear the lawyers closing statements, and then I will provide you with the law to apply in your verdict of guilty or not guilty.

Opening statement from the Crown:

Crown: Mathew Turner arrived at the coffee shop at the corner of Rogers Lane and Randle Avenue in Ottawa around 2:35pm on September $21^{\text {st }}, 2013$. He walked directly to the counter, produced a gun and told Andrea Prentiss, who was at the counter, to place all the cash from the till in a backpack. This offence was witnessed by Dorothy Collins, a customer in the coffee shop. Once the backpack was full, Mr. Turner turned and ran from the shop. He ran down Randle Avenue where he was apprehended by police. Mr. Turner, showed complete disregard for the wellbeing of others. As members of this community, you cannot allow Mr. Turner to continue to wreak havoc. You must seek justice and find Mr. Turner guilty of the armed robbery he committed.

\section{Opening statement from the Defence:}

Defence: Mr. Turner did not rob any store. The guilty parties should be prosecuted but in moments of outrage, we cannot lose sight of justice. Mr. Turner is innocent and is only present today because he meets the vague description given by Mrs. Collins. To bring these charges on Mathew Turner, an innocent man, is unconscionable. As you review the facts, you will ultimately see that Mr. Turner is not responsible for these crimes and is innocent of all charges and reach a not guilty verdict.

Crown calls their first witness, Andrea Prentiss, the coffee shop employee, who takes the stand.

Crown: Please state your full name and your employment for the court.

Witness: My name is Andrea Louise Prentiss and I work at the coffee shop at the corner of Rogers Lane and Randle Avenue.

Crown: Please tell us what happened to you on September $21^{\text {st }}, 2013$.

Witness: On that day, I worked 7:30 am to $3: 30 \mathrm{pm}$. Around 2:30 in the afternoon, a man came into the store. I first noticed him when he pushed to the front of the line. Once he got to the front of the line, he handed me a brown backpack, pointed a gun at me and said "empty the till". I filled the bag as quickly as I could. He then turned and ran out of the store.

Crown: Did you get a clear look at the robber's face? 
Witness: Yes, he was less than 2 feet away from me.

Crown: Do you see the man who held you at gunpoint here today?

Witness: Yes, he is sitting right there \{points to Mr. Turner\}.

Crown: Thank you, no further questions your honour.

Defence cross-examines Miss Prentiss.

Defence: Andrea, how long have you worked at the Café and Crisps coffee shop located at 1128 Randle Avenue?

Witness: I have been a barista there for 6 years.

Defence: How many people do you think you serve on a typical shift?

Witness: Anywhere between 50 to 75, depends on the day.

Defence: Was September $21^{\text {st }}$ a busy day?

Witness: Yes, it was a Saturday, our busiest day.

Defence: So is it safe to say you saw a lot of faces that day?

Witness: Yes.

Defence: And were you afraid when the man pointed the gun at you?

Witness: Yes, of course.

Defence: And if Mr. Turner had been in the shop minutes before the robbery is it not possible that you could have seen his face and a similar looking burglar and confused the faces?

Witness: Anything is possible, but...

Defence: No further questions your honour.

Crown calls their second witness, Detective John Campbell, the lead investigator.

Crown: Please state your full name and position in the local police force.

Witness: Detective John Albert Campbell, I have been a detective on the force for 8 years.

Crown: Please explain how Mr. Turner became a suspect.

Witness: On the afternoon of September $21^{\text {st }}, 2013$, police responded to a 911 call of a robbery at the corner of Rogers Lane and Randle Avenue. When we arrived on scene, officers secured the scene and once the Café and Crisps coffee shop was cleared and a description of the culprit taken, officers began a grid search for the suspect immediately. Mr. Turner was seen darting into an alley, where police officers Sergeant Elsa Hamlin and Constable Stefan Dupuis approached him. He fit the description given by the witnesses and the officers then arrested him.

Crown: Was there anything else discovered in the course of your investigation that suggested that Mr. Turner might be the culprit?

Witness: We found that Mr. Turner had recently been in some financial trouble due to a longterm gambling problem.

Crown: How were you able to positively identify that this was the man who had robbed the coffee shop?

Witness: We put together a lineup consisting of six photos of men who fit the description, one of whom was Mr. Turner. We then showed the lineup to Mrs. Collins, a witness in the coffee shop at the time of the robbery, to see if she could identify the criminal. She made a positive ID, that suspect number four had robbed the coffee shop. Number four was Mr. Turner.

Crown: Was the backpack of cash recovered?

Witness: Yes, we found the backpack in a dumpster on Randle Avenue half way between the café and the alley where Mr. Turner was arrested, it contained approximately $\$ 1,500$.

Crown: Thank you, no further questions your honour.

Defence cross-examines second witness. 
Defence: Was there any evidence that Mr. Turner had been the one to place the backpack in the dumpster?

Witness: No, it was recovered but there were no witnesses; however, based on the location of arrest it did not rule him out as a suspect.

Defence: Where did you present the lineup?

Witness: At Mrs. Collins' home/Long-term care facility.

Defence: Did Mrs. Collins hesitate or seem unsure when making the identification?

Witness: She may have hesitated for a moment but she identified Mr. Turner without question.

Defence: Thank you, no further questions

Crown calls their third witness, Dorothy Collins.

Crown: Please state your full name and profession for the court.

Witness: My name is Mrs. Dorothy Margaret Collins and I am retired but I was a nurse when I was younger.

Crown: And how old are you now Mrs. Collins?

Witness: I am 45/65/85.

Crown: And where do you currently live?

Witness: I live at home, 572 Rogers Lane, Ottawa/ in South Creek Long-Term Care

Facility, 572 Rogers Lane, Ottawa.

Crown: And how is your mental state Mrs. Collins?

Witness: I'm doing well for my age/ Not so good, I have early stage dementia.

Crown: What does doing well/early stage dementia look like for you?

Witness: Well sometimes I lose things such as my keys or lose track of what day of the week it is.

Crown: Where were you on the afternoon of September $21^{\text {st }}, 2013$ ?

Witness: I was at the coffee shop on the corner of Rogers Lane and Randle Avenue, enjoying a latte in the last of the summer weather.

Crown: What did you see while you were having your latte?

Witness: I saw this very rude man push to the front of the line. Then he pulled out a gun and I thought "Oh no! That poor young girl!" But when she filled that brown backpack with the money from the till he ran right out again and I was so relieved.

Crown: What did this man look like?

Witness: He was a young man. White. He had short dark hair and the edges looked like they were just starting to recede.

Crown: And what was he wearing that day?

Witness: He had on a light grey peacoat with a light blue-collared shirt underneath and dark grey slacks.

Crown: And do you see that man here today?

Witness: Well, yes, he is sitting there in the front row \{indicates defendant\}.

Crown: Thank you.

Defence Cross-examines third witness.

Defence: Do you visit the coffee shop often?

Witness: Yes, it's right down the road from my house/the long-term care facility where I live. I like to go a couple times a week after cards.

Defence: And what time is that at usually?

Witness: I usually head that direction around two and arrive between quarter and half past.

Defence: And how long would you say you were inside before the man entered?

Witness: Not a quarter hour I would say. 
Defence: And is it possible that if my client, Mr. Turner, visited that store regularly that you had seen him before?

Witness: Well absolutely, at $\mathbf{4 5 / 6 5 / 8 5}$ I enjoy a good cup of coffee and go there often.

Defence: Is it possible that when you picked his photo out of the lineup that you merely chose a familiar face rather than the person who had robbed the store?

Witness: That is possible, but I think I would recognise that face anywhere.

Defence: No further questions your honour.

Defence calls their first witness, Jessica Baldwin, Mr. Turner's co-worker.

Defence: Please state your full name and occupation for the court.

Witness: My name is Jessica Michelle Baldwin and I work as Mr. Turner's assistant at the bank.

Defence: And how long have you known Mr. Turner for?

Witness: About four years.

Defence: Has Mr. Turner ever done anything at work, which you found to be irresponsible or untrustworthy?

Witness: No, never.

Defence: And would you say robbery and murder were out of character for Mr. Turner?

Witness: Yes, absolutely. I have never even seen him yell.

Defence: No further questions your honour.

Crown cross-examines, Defence's first witness.

Crown: Were you aware that Mr. Turner enjoys poker?

Witness: No, I did not know that.

Crown: In the four years you have known Mr. Turner, has he ever borrowed money from you?

Witness: Yes, from time to time I have lent him money, usually small amounts.

Crown: And has he repaid them promptly in the agreed upon manner?

Witness: Not always promptly, usually he pays back several loans at once.

Crown: And how much did Mr. Turner owe you in September of 2013?

Witness: He owed me two-hundred and thirty dollars.

Crown: How long past the agreed repayment time was he?

Witness: Six weeks.

Crown: Thank you, no further questions.

Defence calls their second witness, the defendant, Mr. Mathew Turner:

Defence: Please state your full name and occupation for the court.

Witness: Mathew Stuart Turner, I work as a manager at the bank.

Defence: Do you like coffee Mr. Turner?

Witness: I do. I usually drink two or three cups a day.

Defence: Where do you usually buy your coffee?

Witness: From the shop at the corner of Roger Lane and Randle Avenue.

Defence: Were you there on September $21^{\text {st }}, 2013$ ?

Witness: Yes, I stopped there in between meetings around 2:20pm.

Defence: And what did you do after?

Witness: I walked back to the bank.

Defence: What caused you to duck into the alleyway when the police drove by?

Witness: There were a lot of cars on the road and I thought that by being away from the edge of the street I would be helping the police make better time.

Defence: When you were arrested what were you doing? 
Witness: Standing in the entrance of the alley, waiting for them to drive by. But they stopped.

Defence: And what were you wearing over your dress shirt?

Witness: A light brown cardigan.

Defence: Thank you, no further questions your honour.

Crown cross-examines Defence's second witness.

Crown: Mr. Turner, who knew about your gambling problems?

Witness: Nobody.

Crown: How did you keep it from your wife?

Witness: I borrowed money until I was on an upturn, then would pay it back.

Crown: Did you owe money to more people than Ms. Baldwin in September 2013?

Witness: Yes.

Crown: No further questions your honour.

Defence calls their third witness, Brittany McInnis.

Defence: Please state your full name and occupation for the court.

Witness: Brittany Mackenzie McInnis, I work for a manufacturing company as a machinist.

Defence: Where were you on the afternoon of September $21^{\text {st }}, 2013$ ?

Witness: I was sitting on my porch.

Defence: And where is your porch located?

Witness: I live at 1122 Randle Avenue.

Defence: And what did you see?

Witness: I saw a man run out of the coffee shop and turn down Randle Avenue going the opposite way.

Defence: Did this man look like Mr. Turner?

Witness: Vaguely, I suppose.

Defence: Could you be absolutely sure that it was Mr. Turner?

Witness: No, there was simply a resemblance.

Defence: Thank you, no further questions.

Crown cross-examines Defence's third witness.

Crown: How far away were you from the running man?

Witness: He was on the other side of the road.

Crown: And is it correct that you were not originally interviewed by the police but came forward later?

Witness: That is correct.

Crown: And this was because the on-duty officers felt that you had not had a sufficient view of the events, is that correct?

Witness: Yes.

Crown: No further questions your honour.

Closing statements:

Crown: Today you have heard a number of testimonies and received information about the robbery that occurred at the coffee shop traumatizing Miss. Prentiss and all others present. You have heard Mr. Turner being identified as the man who committed this crime. Based on this information, you, in your role as juror, must determine whether Mathew Turner is guilty beyond a reasonable doubt. After having heard the reports of a number of eyewitnesses, you can have no 
doubt that Mathew Turner was a desperate man with a gambling addiction who in that desperation held a young woman at gunpoint and robbed the café. He then ran down an alley to hide from the police. The important facts to remember are that Mr. Turner was seen attempting to avoid police and that he had financial motivation to commit this crime; that he is a liar, having hid his gambling problem from his wife for years. Mrs. Collins positively identified Mr. Turner as the robber. With these compelling statements, I urge you to uphold justice and find the accused, Mathew Turner, guilty of armed robbery. Thank you.

Defence: The prosecution has attempted to provide evidence against Mr. Turner that would find him guilty beyond a reasonable doubt, but it is a story that is a house of cards, easily blown down due to the Crown's lack of hard evidence against Mr. Turner. The Crown's evidence against my client is questionable at best. Mr. Turner was only ever considered a suspect because he was in the wrong place at the wrong time and had minor financial problems. With no other person of interest, The Crown, are the desperate ones, attempting to convict an innocent man - Mathew Turner. The evidence is simply insufficient to indicate guilt. Mrs. Collins' testimony should not be considered as she will have been blinded by fear after such trauma and simply picked a familiar face as Mr. Turner frequented the café as she did. There is not sufficient or compelling evidence to go beyond a reasonable doubt. Therefore, I urge you to find Mathew Turner not guilty. Do not let another innocent person be traumatized due to this terrible incident. Thank you.

Judge's instructions to jurors:

Judge: Members of the jury, you have heard the testimony and evidence of both sides. It is now my responsibility to provide you with the law.

Section 343 of the Criminal Code states: Every one commits robbery who:

- (a) steals, and for the purpose of extorting whatever is stolen or to prevent or overcome resistance to the stealing, uses violence or threats of violence to a person or property;

- (b) steals from any person and, at the time he steals or immediately before or immediately thereafter, wounds, beats, strikes or uses any personal violence to that person;

- (c) assaults any person with intent to steal from him; or

- (d) steals from any person while armed with an offensive weapon or imitation thereof.

Please take into consideration all the information you have heard today. Do not allow any personal bias to interfere with your decision making process. It is the facts and only the facts that must be considered when deciding guilt in the court of law. To find the defendant guilty, it must be beyond a reasonable doubt. 


\section{Appendix D: Verdict Form}

Please respond to the following based on the robbery charges against the defendant Mathew Turner.

1. In accordance with section 343 of the Canadian Criminal Code, everyone who steals from any person armed with an offensive weapon is guilty of an indictable offence and liable to a maximum penalty of life in prison. How do you find $\mathrm{Mr}$. Turner?

Guilty Not Guilty

2. How confident do you feel in your verdict?

Not at all confident

12

23

3

4

Very Confident 6

3. If you had to rate Mr. Turner's level of guilt, from 0 (not at all guilty) to 100 (completely guilty, where would you rate his level of guilt?

$\begin{array}{lllllllllll}0 & 10 & 20 & 30 & 40 & 50 & 60 & 70 & 80 & 90 & 100\end{array}$

4. How confident do you feel in this guilt rating?

Not at all confident

1 2

3

4

Very Confident

5

6

5. What is your reason for this verdict? 


\section{Appendix E: Sentencing Form \\ Sentencing (Only if voted guilty)}

1. What punishment, if any, do you believe Mr. Turner Deserves?

Minimum punishment

(4 years)

1

3

4

Maximum allowed

(Life in Prison)

6

2. If you could ignore the Criminal Code, what do you think would be the appropriate sentence and duration of time, if any, for the defendant? (You may refer to the list of sentences available in Canada below to assist you in your answer).

Sentence:

Duration:

Amount (if imposing a fine):

Absolute Discharge: A sentence that releases him or her into the community with no conditions and no criminal record.

Conditional Discharge: A sentence that releases him or her into the community with a set of conditions and no criminal record.

Conditional Sentence of Imprisonment: A prison sentence served in the community under the watch of a supervisor. Conditions can be punitive and usually involve house arrest.

Probation: Offender is released on conditions prescribed in a probation order. Conditions are rehabilitative, not punitive, and directly relate to the offenders' needs. Can be combined with imprisonment.

Fine: A fee made payable to Her Majesty, the province in which the crime is committed. Can be combined with imprisonment.

Imprisonment: A sentence served in an institution. Two years or less is served in provincial jail, two years or more is served in a federal penitentiary. 


\section{Appendix F: Manipulation Check}

1. How old was the eyewitness Dorothy Collins?
a. 25 years old.
b. 45 years old.
c. 65 years old.
d. 85 years old.

2. What did the robber from the coffee shop put the money into?
a. A purse.
b. A duffel bag.
c. A grocery bag.
d. A backpack.

3. Where did the eyewitness Dorothy Collins live?
a. At home.
b. At her daughter's house.
c. At a long-term care facility.
d. At a hotel.

4. What was the culprit wearing when he robbed the coffee shop?
a. A green t-shirt.
b. A blue collared shirt.
c. A black hoodie.
d. A white polo shirt.

5. How was the eyewitness Dorothy Collins aging?
a. She is doing well for her age.
b. She has Alzheimer's.
c. She has early stage dementia,
d. She has late stage Parkinson's. 


\section{Appendix G: Eyewitness Ratings}

1. How credible did you find the eyewitness Dorothy Collins?

Not at all credible

very credible

$\begin{array}{llllll}1 & 2 & 3 & 4 & 5 & 6\end{array}$

2. How reliable did you find the crime details provided by the eyewitness Dorothy Collins?

Not at all reliable

very reliable
1
2
3
4
5

6

3. How believable did you find the eyewitness Dorothy Collins?

Not at all believable

very believable

$\begin{array}{lllllll}1 & 2 & 3 & 4 & 5 & 6\end{array}$

4. How reliable did you find the description of the robber provided by eyewitness Dorothy Collins?

Not at all reliable very reliable
1 2
3
4
5

6

5. How competent did you find the eyewitness Dorothy Collins?

Not at all competent

very competent

1

2

3

4

5

6

6. How accurate did you find the eyewitness Dorothy Collins?

Not at all accurate

very accurate

$\begin{array}{llllll}1 & 2 & 3 & 4 & 5 & 6\end{array}$

7. How reliable did you find the eyewitness Dorothy Collins' identification of Mathew Turner?

Not at all reliable

very reliable

$\begin{array}{lllll}1 & 2 & 3 & 4\end{array}$

8. How confident did you find the eyewitness Dorothy Collins?

Not at all confident

very confident
1
2
3
4
5
9. Overall, how reliable was Dorothy Collins as a witness?

6

Not at all reliable

very reliable
1
2
3
4
5

6

10. How honest did you find the eyewitness Dorothy Collins?

Not at all honest

very honest 
3

4

5

6

11. To what extent did you find the eyewitness Dorothy Collins senile, experiencing or showing the weakness or disease of old age, especially the loss of mental faculties?

Not at all senile

very senile

1

2

3

4

5

6 


\section{Appendix H: Opinion Scales}

1. What do you think is the reason people move to a long-term care facility? Select all that apply.

Old age

Geriatric diagnosis (ex. Alzheimer's, Parkinson's, etc.)

Mobility issues

Difficulty caring for themselves

Physical trauma

Need nursing care

Decreased cognitive aptitude

Greater social life

Routine activities

Carefree living

Access to exercise groups/facilities

Peace of mind

2. What do you think is the number one reason people move to a long-term care facility? Select one.

Old age

Geriatric diagnosis (ex. Alzheimer's, Parkinson’s, etc.)

Mobility issues

Difficulty caring for themselves

Physical trauma

Need nursing care

Decreased cognitive aptitude

Greater social life

Routine activities

Carefree living

Access to exercise groups/facilities

Peace of mind

3. Which adjectives describe the type of people who live in long-term care facilities? Select all that apply. 
Old

Senile

Disabled

Frail

Confused

Healthy

Social

Active

Carefree

4. Which adjective best describes the type of people who live in long-term care facilities? Select one.

Old

Senile

Disabled

Frail

Confused

Healthy

Social

Active

Carefree

5. Do you know anyone who lives in a long-term care facility?

No ___ Yes, if yes what is their relation to you

6. What type of care do you believe a long-term care facility provides?

7. Which of the following symptoms do you think are associated with early stage dementia? Select all that apply.

Forgetting 
Confusion

Physical disability

Tremors

Hallucinations

8. What is someone with dementia like?

9. Do you know anyone who has dementia?

No ___ Yes, if yes what is their relation to you and how advanced is it 


\section{Appendix I: Stereotypes Toward Older People Scale (STOPS) Stereotypes Towards Older People Scale (STOPS)}

Please read each statement below and indicate the number which best describes to what extent you believe each statement is true of older persons. If you feel the adjective always describes the elderly indicate 7; if you feel the adjective never describes the elderly indicate 1; if you feel somewhere in between indicate any one of the numbers between 1 and 7. If you neutral or undecided, the midpoint is 4.

1. Old people are set in their ways:

$\begin{array}{ccccccc} & & \text { Some of } & \text { Most of } & \text { Almost } & \\ \text { Never } & \text { Rarely } & \text { Occasionally } & \text { the time } & \text { the time } & \text { always } & \text { Always } \\ 1 & 2 & 3 & 4 & 5 & 6 & 7\end{array}$

2. Old people are meddlesome:

$\begin{array}{ccccccc} & & \text { Some of } & \text { Most of } & \text { Almost } & \\ \text { Never } & \text { Rarely } & \text { Occasionally } & \text { the time } & \text { the time } & \text { always } & \text { Always } \\ 1 & 2 & 3 & 4 & 5 & 6 & 7\end{array}$

3. Old people are old-fashioned:

$\begin{array}{ccccccc} & & \text { Some of } & \text { Most of } & \text { Almost } & \\ \text { Never } & \text { Rarely } & \text { Occasionally } & \text { the time } & \text { the time } & \text { always } & \text { Always } \\ 1 & 2 & 3 & 4 & 5 & 6 & 7\end{array}$

4. Old people think about the good old days:

$\begin{array}{ccccccc} & & & \text { Some of } & \text { Most of } & \text { Almost } & \\ \text { Never } & \text { Rarely } & \text { Occasionally } & \text { the time } & \text { the time } & \text { always } & \text { Always } \\ 1 & 2 & 3 & 4 & 5 & 6 & 7\end{array}$

5. Old people never fully recover from illness:

$\begin{array}{ccccccc} & & & \text { Some of } & \text { Most of } & \text { Almost } & \\ \text { Never } & \text { Rarely } & \text { Occasionally } & \text { the time } & \text { the time } & \text { always } & \text { Always } \\ 1 & 2 & 3 & 4 & 5 & 6 & 7\end{array}$


6. Old people are physically active:

$\begin{array}{ccccccc} & & \text { Some of } & \text { Most of } & \text { Almost } & \\ \text { Never } & \text { Rarely } & \text { Occasionally } & \text { the time } & \text { the time } & \text { always } & \text { Always } \\ 1 & 2 & 3 & 4 & 5 & 6 & 7\end{array}$

7. Old people are grouchy (cranky):

$\begin{array}{ccccccc} & & \text { Some of } & \text { Most of } & \text { Almost } & \\ \text { Never } & \text { Rarely } & \text { Occasionally } & \text { the time } & \text { the time } & \text { always } & \text { Always } \\ 1 & 2 & 3 & 4 & 5 & 6 & 7\end{array}$

8. Old people talk to themselves:

$\begin{array}{ccccccc} & & \text { Some of } & \text { Most of } & \text { Almost } & \\ \text { Never } & \text { Rarely } & \text { Occasionally } & \text { the time } & \text { the time } & \text { always } & \text { Always } \\ 1 & 2 & 3 & 4 & 5 & 6 & 7\end{array}$

9. Old people get upset easily:

Some of Most of Almost

Never Rarely Occasionally the time the time always Always

$\begin{array}{lllllll}1 & 2 & 3 & 4 & 5 & 6 & 7\end{array}$

10. Old people are productive:

$\begin{array}{ccccccc} & & \text { Some of } & \text { Most of } & \text { Almost } & \\ \text { Never } & \text { Rarely } & \text { Occasionally } & \text { the time } & \text { the time } & \text { always } & \text { Always } \\ 1 & 2 & 3 & 4 & 5 & 6 & 7\end{array}$

11. Old people are optimistic:

Some of Most of Almost

Never Rarely Occasionally the time the time always Always

$\begin{array}{llllll}1 & 2 & 3 & 4 & 5 & 6\end{array}$

$6 \quad 7$

12. Old people walk slowly:

$\begin{array}{ccccccc} & & & \text { Some of } & \text { Most of } & \text { Almost } & \\ \text { Never } & \text { Rarely } & \text { Occasionally } & \text { the time } & \text { the time } & \text { always } & \text { Always } \\ 1 & 2 & 3 & 4 & 5 & 6 & 7\end{array}$

13. Old people have health problems: 


$\begin{array}{ccccccc} & & \text { Some of } & \text { Most of } & \text { Almost } & \\ \text { Never } & \text { Rarely } & \text { Occasionally } & \text { the time } & \text { the time } & \text { always } & \text { Always } \\ 1 & 2 & 3 & 4 & 5 & 6 & 7\end{array}$

14. Old people are intolerant (impatient):

$\begin{array}{ccccccc} & & \text { Some of } & \text { Most of } & \text { Almost } & \\ \text { Never } & \text { Rarely } & \text { Occasionally } & \text { the time } & \text { the time } & \text { always } & \text { Always } \\ 1 & 2 & 3 & 4 & 5 & 6 & 7\end{array}$




\section{Appendix J: Debriefing Form \\ You Be The Juror! Debriefing Form}

The purpose of a debriefing form is to ensure that at the end of a study you know more than you did in the beginning and to provide you with any resources which are available to you in case you have further questions or concerns about this study. This study has been approved by the Carleton University Ethics Committee for Psychological Research and assigned \#15-076

What are we trying to learn in this research? The purpose of the current study is to assess the extent to which an individual's stereotypes about the elderly effect their decision making in a judicial setting. Research in this area will allow those in the criminal justice system to understand the effects of having an eyewitness who is required to testify. The current study also sought to examine potential interactions between the witness' age (i.e., 45, 65, 85), whether the witness lives at home or in a long-term care facility, and whether they have early stage dementia. Specifically, we were interested in whether a middle aged ( 45 years), older adult ( 65 years), and an elderly ( 85 years) witness would be perceived differently. The trial transcript you read was not from a real trial and was created for the specific research purposes.

Why was the use of deception necessary? At the beginning of this study, it was stated that the purpose was to assess an individual's ability to evaluate and process trial information. This was not entirely true. In this case deception, or the intentional omission of information, was used to avoid telling you the specific purpose of the study in advance. We were not able to tell you the specifics of what we were looking at before because it might have changed the way you answered questions or the information which you attended to in the transcript. Mock jurors could have been influenced to respond in a way which they perceive to be socially acceptable. If this deception has changed your decision to participate you may still withdraw without penalization. 
What are the hypotheses and predications? Our hypothesis is that older adults, those living in long-term care facilities, and those with dementia will be seen as less reliable and will elicit more not guilty verdicts from mock jurors. These factors when found together will elicit an even greater effect.

\section{Where can I learn more?}

Golding, J. M., Wasarhaley, N. E. (2008). How is elder abuse perceived in the courtroom? http://www.nlrc.aoa.gov/Legal Issues/Elder Abuse/docs/golding art elder abus e courtroom.pdf

Nunez, N., McCoy, M. L., Clark, H. L., \& Shaw, L. A. (1999). The testimony of elderly victim/witnesses and their impact on juror decisions: The importance of examining multiple stereotypes. Law and Human Behavior, 23(4), 413-423. Full text available at http://www.researchgate.net/publication/227133166_The Testimony_of_Elderly VictimWitnesses_and_Their_Impact_on_Juror_Decisions_The_Importance_of_E xamining_Multiple_Stereotypes

What if I have questions or concerns later? If you have questions about this research, you can contact the following researchers at any time: Masters candidate Elizabeth Schultheis (elizabethschultheis@,cmail.carleton.ca). You may also contact the research supervisor Dr. Joanna Pozzulo (Joanna.Pozzulo@carleton.ca, 613-520-2600, ext. 8218) from the Department of Psychology. Should you have any ethical concerns about this study, you may contact Dr. Shelley Brown (Chair, Carleton University Ethics Committee for Psychological Research, shelley.brown@,carleton.ca, 613-520-2600 ext. 1505). For any other concerns, please contact Dr. Joanna Pozzulo (Chair, Department of Psychology, Joanna.Pozzulo@,carleton.ca, 613-520-2600 ext. 8218).

Is there anything I can do if I found this emotionally draining? Yes. If this experiment has caused you any distress that persists for more than five minutes, please contact The Mental Health Helpline 1-800-273-8255 or visit http://www.mentalhealthhelpline.ca 
Thank you for participating in this study! 


\section{Appendix K: Consent to Keep Data \\ Consent to Keep Data: You Be The Juror!}

The purpose of a consent to keep data is to ensure that you have the opportunity to make an informed decision to participate in the study now that you know the true purpose. Now that you know the true purpose and are aware that deception was used, we want to give you the opportunity to withdraw your data from the study. Should you wish to withdraw your data will immediately be destroyed. This study has been approved by the Carleton University Ethics Committee for Psychological Research and assigned \#15-076

By completing the following you indicate that you understand that during your participation you were not aware of the true purpose of the study and that you understand why the deception was necessary.

Please indicate whether you do / do not continue to consent to the use of your data.

I consent to the use of my data.

I do not consent to the use of my data.

Thank you for participating in this study! 